\title{
Population Pharmacokinetic-B Cell Modeling for Ofatumumab in Patients with Relapsing Multiple Sclerosis
}

\author{
Huixin Yu ${ }^{1}$. Gordon Graham ${ }^{1}$ - Olivier J. David ${ }^{1}$. Joseph M. Kahn ${ }^{2}$ - Marina Savelieva ${ }^{1}$. Etienne Pigeolet ${ }^{1}$. \\ Ayan Das Gupta $^{3} \cdot$ Ratnakar Pingili $^{2} \cdot$ Roman Willi $^{1} \cdot$ Krishnan Ramanathan $^{1} \cdot$ Bernd C. Kieseier ${ }^{1,4}$ - Dieter A. Häring ${ }^{1}$. \\ Morten Bagger ${ }^{1} \cdot$ Per Soelberg Sørensen ${ }^{5}$
}

Accepted: 21 December 2021 / Published online: 1 March 2022

(c) The Author(s) 2022

\begin{abstract}
Background Ofatumumab, a fully human anti-CD20 monoclonal antibody indicated for the treatment of relapsing forms of multiple sclerosis (RMS), binds to a unique conformational epitope, thereby depleting B cells very efficiently and allowing subcutaneous administration at lower doses.

Objectives The aims were to characterize the relationship between ofatumumab concentration and B cell levels, including the effect of covariates such as body weight, age, or baseline B cell count, and use simulations to confirm the chosen therapeutic dose. Methods Graphical and regression analyses previously performed based on data from a dose-range finding study provided the B cell depletion target used in the present work. All available adult phase 2/3 data for ofatumumab in RMS patients were pooled to develop a population pharmacokinetics (PK)-B cell count model, using nonlinear mixed-effects modeling. The population PK-B cell model was used to simulate B cell depletion and repletion times and the effect of covariates on PK and $\mathrm{B}$ cell metrics, as well as the dose response across a range of subcutaneous ofatumumab monthly doses.

Results The final PK-B cell model was developed using data from 1486 patients. The predetermined B cell target was best achieved and sustained with the 20-mg dose regimen, with median B cell count reaching 8 cells/ $\mu \mathrm{L}$ in 11 days and negligible repletion between doses. Only weight had a significant effect on PK, which did not translate into any clinically relevant effect on B cell levels. Conclusion The PK-B cell modeling confirms the dose chosen for the licensed ofatumumab regimen and demonstrates no requirement for dose adjustment based on adult patient characteristics.
\end{abstract}

\section{Key Points}

Ofatumumab is a fully human anti-CD20 monoclonal antibody for patients with relapsing multiple sclerosis that is self-administered, with a once-monthly injection, delivered subcutaneously. Ofatumumab works by binding to a distinct epitope on the CD20 molecule, inducing potent $\mathrm{B}$ cell lysis and depletion.

Gordon Graham

gordon.graham@novartis.com

Novartis Pharma AG, Postfach CH-4002, Basel, Switzerland

2 Novartis Pharmaceuticals Corporation, East Hanover, NJ, USA

3 Novartis Healthcare Pvt. Ltd., Hyderabad, India

4 Department of Neurology, Medical Faculty, Heinrich-Heine University, Duesseldorf, Germany

5 Department of Neurology, Danish Multiple Sclerosis Center, University of Copenhagen, Rigshospitalet, Copenhagen, Denmark

In this study, we developed a model (using data from five phase 2 and 3 studies) characterizing the relationship between $\mathrm{B}$ cell count and plasma concentration of ofatumumab.

Simulations based on this model confirm that the 20-mg dose regimen results in an optimal and sustained B cell depletion, with B cell target reached in 11 days. The simulations also indicate that no dose adjustment is needed based on patient characteristics such as age, weight, or baseline B cell levels. Altogether, these findings confirm the dose chosen for the licensed ofatumumab regimen. 


\section{Introduction}

Multiple sclerosis (MS) is a chronic autoimmune disorder that affects the central nervous system. B cells are involved in the pathogenesis of immune-mediated diseases, including MS, through a number of mechanisms [1-4]. In MS, $\mathrm{B}$ cells have been proposed to act via antibody production and antigen presentation for the activation of $\mathrm{T}$ cells, but also as an essential source of pro-inflammatory cytokines, which together can lead to the orchestrated inflammatory infiltration of the central nervous system. Targeted depletion of $\mathrm{CD} 20+\mathrm{B}$ cells is an effective method of suppressing inflammatory activity in MS while sparing protective immunity [5].

Ofatumumab is a fully human anti-CD20 monoclonal antibody, with a 20-mg subcutaneous (SC) monthly dosing regimen that has been approved in the United States (US), the European Union (EU), and several other countries for the treatment of relapsing forms of MS (RMS), to include clinically isolated syndrome, relapsing-remitting disease, and active secondary progressive disease in adults (US) [6], or in adults with active disease defined by clinical or imaging features (EU) [7]. B cell lysis resulting from ofatumumab binding primarily occurs through complement-dependent cytotoxicity and antibody-dependent cell-mediated cytotoxicity.

Unlike rituximab and ocrelizumab, which only bind to the large extracellular loop of the CD20 antigen, ofatumumab binds to two distinct regions within the large and small extracellular loops [8]. Such binding on a unique conformational epitope is characterized by a low off-rate and greater complement-dependent cytotoxicity [8]. As a result, ofatumumab has higher potency compared with these earlier anti-CD20s, depleting B cells more efficiently, thereby allowing for SC administration at lower doses [9].

The initial phase 2 program for ofatumumab included two placebo-controlled studies in patients with relapsingremitting MS (RRMS). Study OMS115102 of ofatumumab administered intravenously (IV) suggested a clinically meaningful effect of ofatumumab (> 99\% reduction in new gadolinium-enhancing (Gd-enhancing) T1 lesions at weeks 8-24), with no unexpected safety concerns [10]. The subsequent MIRROR SC dose-finding study (OMS112831) demonstrated a rapid, dose-dependent reduction in B cell counts and a reduction in Gd-enhancing $\mathrm{T} 1$ lesions by over $90 \%$ (cumulative doses $\geq 30 \mathrm{mg}$ given every 12 weeks [q12w] $\mathrm{SC)}$ relative to placebo [11].

The efficacy and safety of ofatumumab have been confirmed in two identically designed pivotal phase 3 studies versus the active comparator teriflunomide (ASCLEPIOS I and II [COMB157G2301 and COMB157G2302]) in patients with RMS [12]. In these phase 3 studies, ofatumumab-administered using the SC regimen of 20-mg initial loading doses given at day 1,7 , and 14 , followed by subsequent monthly (q4w) 20-mg dosing starting at week 4 (no dose on day 21 [week 3]) — was associated with a rapid and sustained B cell depletion over 96 weeks during active treatment [12]. This resulted in a 51-58\% reduction in the number of clinical relapses (as assessed by the annualized relapse rate; primary endpoint), a $94-97 \%$ reduction in the number of Gdenhancing $\mathrm{T} 1$ lesions, and a $34-35 \%$ reduction in the risk of 3-month confirmed disability worsening, versus teriflunomide $14 \mathrm{mg}$ once daily. Additionally, the phase 2 APLIOS study (COMB157G2102), while demonstrating the pharmacokinetic (PK) bioequivalence of ofatumumab injected by the prefilled syringe (PFS) versus an auto-injector (AI) pen (Sensoready ${ }^{\circledR}$ Pen), also showed that ofatumumab administered using the same dosing regimen as the phase 3 studies resulted in a rapid and close to complete B cell depletion over 12 weeks [13]. Finally, a phase 2 study comparing ofatumumab $20 \mathrm{mg}$ SC and placebo in Japanese versus non-Japanese RMS patients (APOLITOS [COMB157G1301]) has also been completed since this analysis was performed, and will be discussed in the context of our findings.

In a previous work, a B cell-magnetic resonance imaging (MRI) lesion model was developed based on the MIRROR phase 2 dose-finding study (AAN 2017 [14]). The results of this analysis along with dose-B cell modeling based on the same data (ACTRIMS-ECTRIMS 2017 [15]) provided both the target for $\mathrm{B}$ cell depletion and the rationale for dose regimen selection in phase 3 trials (Savelieva et al., 2021; manuscript in preparation).

In the present work, data from all five studies, representing all the RMS studies that included ofatumumab plasma concentration and B cell data available at the time of this analysis, were pooled to develop a pharmacokinetic-pharmacodynamic (PKPD) model of the ofatumumab concentration-B cell count relationship. Our approach included the following steps:

1. Present the relationship between $B$ cell levels and lesion suppression, including the level of B cell depletion required for maximal suppression of Gd-enhancing T1 lesions.

2. Characterize the PKPD relationship between the ofatumumab drug concentrations and B cell counts in RMS patients.

3. Predict and compare ofatumumab PK and B cell dynamics given different dose regimens, including the phase 3 dose regimen, through PK-B cell model simulations. In particular, the pharmacodynamics (PD) were assessed for their ability to attain the target B cell count determined in the first step; the dynamics of B cell repletion after dose discontinuation were also assessed. 
4. Explore the effect of covariates, such as body weight, age, administration route (IV vs. SC), SC injection device, and baseline $\mathrm{B}$ cell count, on the $\mathrm{PK}$ and $\mathrm{B}$ cell dynamics. Based on these findings, the present paper will draw conclusions regarding the optimal dose regimen for ofatumumab in RMS, including different patient subgroups.

\section{Methods}

\subsection{Data}

The analysis of ofatumumab plasma concentration and B cell counts over time was performed using data from five studies of ofatumumab (three phase 2 and two phase 3 ), as described in Table 1 .

Ofatumumab concentrations were quantified in plasma with a validated chemiluminescence assay (enzyme-linked immunosorbent assay [ELISA]) using a mouse anti-ofatumumab idiotypic antibody for capture and a horseradish peroxidase (HRP) conjugated mouse anti-human IgG1 (Fcspecific) antibody followed by the addition of a chromogenic substrate for detection. The lower limit of quantification (LLOQ) varied by study, with a value of $0.1 \mathrm{mg} / \mathrm{L}$ for studies OMS115102 and MIRROR and $0.05 \mathrm{mg} / \mathrm{L}$ for studies APLIOS and ASCLEPIOS I and II.

$B$ cell kinetics were assessed with routine fluorescenceactivated cell sorter analysis using another B cell-specific surface protein, CD19. Cell counts down to 0 cells/ $\mu \mathrm{L}$ were quantified in APLIOS and ASCLEPIOS I and II, and as low as 5 cells/ $\mu \mathrm{L}$ in OMS115102 and MIRROR.

B cell data from ASCLEPIOS I and II were reported to a different number of significant digits than the other studies. B cell counts were rounded to the nearest 10 cell/ $\mu \mathrm{L}$ such that a B cell count of, for example, 0,10 , and 20 cells $/ \mu \mathrm{L}$ corresponded to interval-censored data with limits $(0,<5)$, $(5,<15)$, and $(15,<25)$, respectively. It was decided to model the ASCLEPIOS B cell data as interval censored.

Data below the LLOQ for the PK and B cells, and the interval-censored $\mathrm{B}$ cell data in the phase 3 studies were handled as explained in https://monolix.lixoft.com/data-andmodels/censoreddata [16].

All concentration and B cell count data were included in the analysis. Missing covariate data were imputed to the median value of the population.

\subsection{B Cell-Depletion Target}

Graphical and regression analyses of data from 231 patients in the MIRROR study had previously been used to investigate the relationship between CD19+ B cell counts and reduction in cumulative Gd-enhancing $\mathrm{T} 1$ lesion volumes at week 24 under ofatumumab administration (AAN 2017 [14]) (Savelieva et al., 2021; manuscript in preparation). Firstly, new cumulative Gd-enhancing T1 lesion volume data were plotted versus the mean B cell count from week 4 to week 20 (during which time most patients had reached their maximum level of $\mathrm{B}$ cell depletion). Patients were binned into three B cell groups $(\leq 8,>8-32$, and $>32$ cells $/ \mu \mathrm{L})$ and also grouped by baseline Gd-enhancing T1 lesion count ( 0 or $\geq 1$ lesion). The cumulative lesion volume was used rather than the cumulative lesion count as it allowed for a better signal detection based on preliminary data exploration.

Secondly, in order to characterize the relationship between the extent of B cell count reduction and MRI activity, a negative binomial regression model related the cumulative volumes of new Gd-enhancing T1 lesions to three key factors: (1) the average B cell levels from weeks 4 to 20 , (2) the number of lesions at screening ( 0 or $\geq 1$ lesion),

Table 1 Characteristics of the studies included in the PKPD model development

\begin{tabular}{|c|c|c|c|c|c|}
\hline Studies & Phase & Patients $^{\mathrm{a}}$ & $\begin{array}{l}\text { Administra- } \\
\text { tion route } \\
\text { and device }\end{array}$ & Ofatumumab dosage regimen & Study duration \\
\hline OMS115102 [10] & 2 & RRMS $; N=25$ & IV & 100,300 , or $700 \mathrm{mg}$ at week 0 and 2 or at week 24 and 26 & 48 weeks + FU \\
\hline MIRROR [11] & 2 & RRMS; $N=231$ & SC by PFS & $0,3,30$, or $60 \mathrm{mg} \mathrm{q} 12 \mathrm{w}$ or $60 \mathrm{mg} \mathrm{q} 4 \mathrm{w}$ & 48 weeks + FU \\
\hline APLIOS [13] & 2 & $\mathrm{RMS} ; N=284$ & $\begin{array}{l}\text { SC by PFS } \\
\quad(N=143) \\
\text { or } \mathrm{AI}(N= \\
141)\end{array}$ & Same as for ASCLEPIOS & 12 weeks \\
\hline ASCLEPIOS I and II [12] & 3 & $\mathrm{RMS} ; N=946$ & SC by PFS & $20 \mathrm{mg} \mathrm{q} 4 \mathrm{w}$ after $20-\mathrm{mg}$ initial doses at days 1,7 , and 14 & $\begin{array}{l}\text { Up to } 120 \\
\text { weeks (30 } \\
\text { months) }\end{array}$ \\
\hline
\end{tabular}

$A I$ auto-injector, $F U$ follow-up, $I V$ intravenous, $N$ number of patients from each study who were included in the final model, $P F S$ prefilled syringe, $P K P D$ pharmacokinetic-pharmacodynamic, $R M S$ relapsing multiple sclerosis, $R R M S$ relapsing-remitting multiple sclerosis, $S C$ subcutaneous, $q 4 w$ every 4 weeks, $q 12 w$ every 12 weeks

${ }^{a}$ Patients treated with ofatumumab and with B cell data who were included in the final model 
and (3) the different ofatumumab treatment groups. In this model, the effect of B cell count on MRI lesion reduction was described by a maximum drug effect $\left(E_{\max }\right)$ function (modeling details in poster AAN 2017 [14] available on demand). A target B cell count was chosen based on the graphical and regression analyses results (AAN 2017 [14]) (Savelieva et al., 2021; manuscript in preparation).

\subsection{PKPD Modeling and Simulation}

The PKPD modeling and simulation consisted of four major steps, including two for the modeling part and two for the simulation part:

1. A base structural population PK-B cell count model was developed to assess the relationship between PK and B cells. Three main types of model were used as starting models: the target-mediated drug disposition (TMDD) model after Struemper et al. [17]; the binding model and its approximations with the B cell count as the target [18]; and the binding model and its approximations to describe the concentration data, with an indirect response model to describe the B cell count dynamics. All models were fitted to the concentration and B cell data simultaneously using Monolix (v.2019R2). The final base model evaluation was assessed by using likelihood-based criteria $(-2 \times \log$-likelihood (LL), Akaike's Information Criteria (AIC), Bayesian Information Criteria (BIC)), goodness-of-fit plots, parameter estimation convergence, the precision and correlations of parameter estimates, and the distribution of random effects using five samples from the conditional distribution to account for the uncertainty in the empirical Bayes estimates (https://monolix.lixoft. com/tasks/conditional-distribution).

Time effects in the PK were tested in the different structural models by including a time component of the form $\theta(t)=\theta_{\infty}+\left(\theta_{0}-\theta_{\infty}\right) e^{-\frac{k_{\text {des }}}{365.25}}$, where $\theta_{0}$ and $\theta_{\infty}$ are the parameter values at time 0 and infinity, respectively, and $k_{\text {des }}$ is the time rate constant on receptor synthesis rate constant. This time-effect model was tested on the bioavailability $(F)$, clearance $(\mathrm{CL})$, and target synthesis rate parameters.

2. A covariate analysis was performed using a priori selected covariate-parameter relationships, as well as covariate-parameter relationships significant at the $p=$ 0.001 level using the Pearson correlation and analysis of variance (ANOVA) tests for continuous and categorical covariates, respectively, in order to select a full covariate model. The a priori covariates were selected based on an initial population PK analysis of the PK data from the five studies and included the following covariateparameter relationships: baseline weight on CL, central volume of distribution $\left(V_{\mathrm{c}}\right)$, intercompartmental flow $(Q)$, absorption rate constant $\left(k_{\mathrm{a}}\right)$, elimination rate constant for complex $\left(k_{\mathrm{e}(\mathrm{P})}\right)$, synthesis rate constant at time 0 $\left(k_{\mathrm{syn} 0}\right)$; sex on $F$; $\mathrm{AI}$ on $k_{\mathrm{e}(\mathrm{P})}$; and IV administration route on $k_{\mathrm{syn} 0}$.

Candidate covariates to determine the full model included baseline body weight, baseline age, gender, race, route of administration, SC injection device, baseline B cell count, and study. The parameter-covariate relationships that were included in the full model were selected by visualizing the conditional distribution samples versus covariate scatter plots, as well as covariate-parameter relationships significant at the $p=$ 0.001 level using the Pearson correlation and ANOVA tests for continuous and categorical covariates, respectively, also using the conditional distribution samples [Statistical tests for model building on Monolix (lixoft. com)]. A one-at-a-time backward elimination procedure was then performed to obtain a final model by reducing the covariate model to include only covariates with significant effects based on the Wald test at the $p=0.001$ level. Outputs from Monolix were used to perform this covariate analysis.

3. Simulations were performed using the final PK-B cell model for the general RMS population-i.e., all the patients observed across the five studies included in the modeling dataset - with the drug administered SC using the PFS (since this was the primary studied route of administration and device, and provided the largest amount of data for the model development). The relationships between ofatumumab doses and $\mathrm{B}$ cell response at 7 days, 28 days, 3 months, 6 months, 1 year, and 2 years were simulated across a range of ofatumumab doses $(1,2,5,10,20$, or 40 $\mathrm{mg}$ ) administered with the phase 3 dosing regimen (schedule used in the phase 3 regimen, i.e., three initial loading doses given weekly followed by monthly doses starting from week 4)—referred to as the 'monthly schedule.'

The ofatumumab concentration profile and B cell count dynamics were then simulated using the phase 3 dosing regimen (i.e., three initial loading doses of $20 \mathrm{mg}$ administered weekly followed by monthly $20-\mathrm{mg}$ doses from week 4-referred to as 'monthly 20-mg regimen').

4. The clinical relevance of the covariates selected for the final model were assessed (assuming the phase 3 dose regimen with SC PFS administration) by simulating their effect on (1) the steady state PK metrics area under the curve (AUC) after 2 years after the start of dosing and (2) B cell metrics 2 years after start of dosing (at day 728) and time to return to the lower limit of normal (LLN) (40 cells $/ \mu \mathrm{L})$ after dosing stops at 2 years. For this purpose, 1000 patients were simulated from the inter-individual random effects distribution at the 5th and 95th percentiles of the patient covariate distributions 
of baseline weight, age, and B cell count (observed in the pooled data from the five studies).

When simulation of each covariate effect was performed, the other covariates included in the final model were fixed to the median value or typical values, if categorical.

The steps are summarized in Fig. 1. Nonlinear mixedeffects modeling was performed using Monolix (v.2019R2) and R (v.3.6.1) programs.

\section{Results}

\subsection{Summary Statistics}

All studies included adult RMS patients with an Expanded Disability Status Scale (EDSS) score of 0-5.5 at screening. Baseline summary statistics of the covariates used in the analyses, as well as additional baseline measures including EDSS and measures of inflammatory status and subclinical disease burden, were broadly similar among the five studies (Table 2).

\subsection{Data}

\subsubsection{PK Data}

A total of 9168 plasma concentrations provided by 1440 patients with RMS were included in the PK analysis. PK data of the placebo group were removed, as well as missing PK data, accounting for the difference between 1440 and the total number of patients (1486). In addition, since there was an underprediction in the 700-mg group found in all PK models tested, which was not the case for any of the other doses, and since, in addition, $700 \mathrm{mg}$ was considered to be distant from the selected therapeutic SC dose regimen, it was decided not to include this dose in the analysis. Data corresponding to rich PK profiles were available from 320 patients in studies OMS115102 and APLIOS, providing 4294 concentrations, of which 598 were below the limit of quantification (BLOQ) (14\%). The MIRROR study had a placebo arm and four dose regimens, including 3, 30, and $60 \mathrm{mg} \mathrm{q} 12 \mathrm{w}$ as well as $60 \mathrm{mg}$ q4w, providing 650 concentrations, of which 461 were BLOQ (71\%). The phase 3 studies ASCLEPIOS I and II provided mainly pre-dose concentrations, with a median of five samples per participant from 912 patients and a total of 4495 concentrations, of which 570 were BLOQ (13\%).

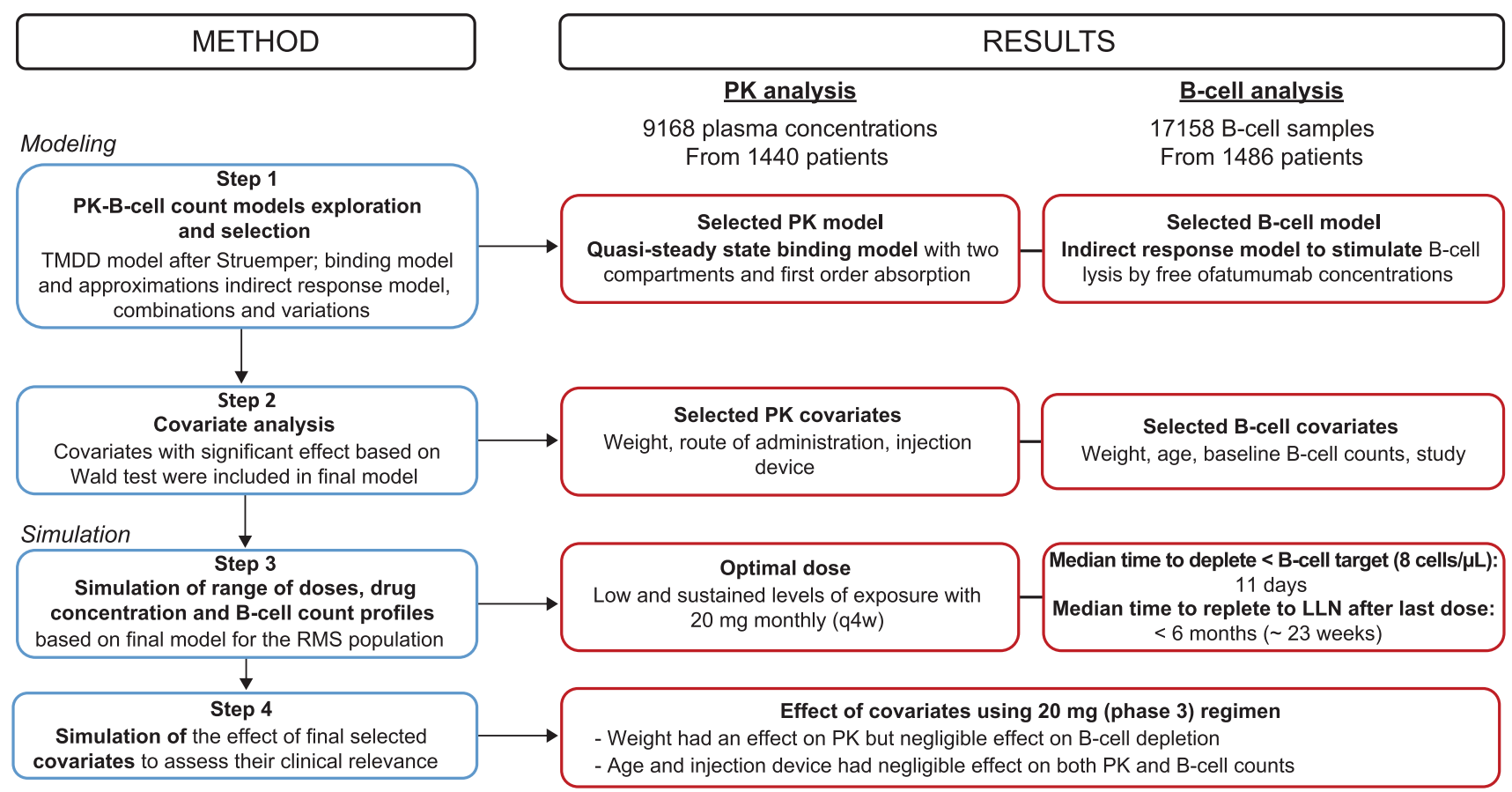

Fig. 1 Modeling steps and results. $L L N$ lower limit of normal, $P K$ pharmacokinetics, $q 4 w$ every 4 weeks, $R M S$ relapsing multiple sclerosis, $T M D D$ target-mediated drug disposition 
Table 2 Covariate summary statistics at baseline by study

\begin{tabular}{|c|c|c|c|c|c|c|}
\hline Variable $(N)$ & OMS115102 (25) & MIRROR (231) & APLIOS (284) & $\begin{array}{l}\text { ASCLEPIOS I } \\
(465)\end{array}$ & $\begin{array}{l}\text { ASCLEPIOS II } \\
(481)\end{array}$ & All (1486) \\
\hline $\begin{array}{c}\text { Route of adminis- } \\
\text { tration (IV, PFS } \\
[\mathrm{SC}] \text { or AI }[\mathrm{SC}])\end{array}$ & $\begin{array}{l}\mathrm{AI}=0 \\
\mathrm{PFS}=0 \\
\mathrm{IV}=25\end{array}$ & $\begin{array}{l}\mathrm{AI}=0 \\
\mathrm{PFS}=231 \\
\mathrm{IV}=0\end{array}$ & $\begin{array}{l}\mathrm{AI}=141 \\
\mathrm{PFS}=143 \\
\mathrm{IV}=0\end{array}$ & $\begin{array}{l}\mathrm{AI}=0 \\
\mathrm{PFS}=465 \\
\mathrm{IV}=0\end{array}$ & $\begin{array}{l}\mathrm{AI}=0 \\
\mathrm{PFS}=481 \\
\mathrm{IV}=0\end{array}$ & $\begin{array}{l}\mathrm{AI}=141 \\
\mathrm{PFS}=1320 \\
\mathrm{IV}=25\end{array}$ \\
\hline Age (years) & $\begin{array}{l}36.2(7.5) \\
33[26-52]\end{array}$ & $\begin{array}{l}37.1(9.4) \\
38[18-56]\end{array}$ & $\begin{array}{l}37.3(8.9) \\
37[18-55]\end{array}$ & $\begin{array}{l}38.9(8.8) \\
40[19-56]\end{array}$ & $\begin{array}{l}38.0(9.3) \\
38[18-56]\end{array}$ & $\begin{array}{l}37.9(9.1) \\
38[18-56]\end{array}$ \\
\hline Weight (kg) & $\begin{array}{l}73.6(14.9) \\
76.0[48.0-104.0]\end{array}$ & $\begin{array}{l}73.4(17.0) \\
70.0[42.0-136.0]\end{array}$ & $\begin{array}{l}73.7(18.4) \\
70.0[44.6-168.0]\end{array}$ & $\begin{array}{l}74.8(19.9) \\
70.2[41.2-171.5]\end{array}$ & $\begin{array}{l}73.6(19.0) \\
70.0[40.5-157.9]\end{array}$ & $\begin{array}{l}74.0(18.8) \\
70.0[40.5-171.6]\end{array}$ \\
\hline Sex (\% female $)$ & 64.0 & 67.1 & 70.1 & 68.4 & 66.3 & 67.8 \\
\hline \multicolumn{7}{|l|}{ Race $(n)$} \\
\hline White/Caucasian & 25 & 225 & 275 & 411 & 418 & 1354 \\
\hline $\begin{array}{l}\text { Black/African } \\
\text { American }\end{array}$ & 0 & 2 & 6 & 15 & 13 & 36 \\
\hline Asian & 0 & 1 & 0 & 15 & 21 & 37 \\
\hline Unknown & 0 & 0 & 0 & 2 & 9 & 11 \\
\hline $\begin{array}{l}\text { Other/American } \\
\text { Indian or Alaska } \\
\text { Native }\end{array}$ & 0 & 3 & 3 & 22 & 20 & 48 \\
\hline $\begin{array}{l}\text { CD19+ B cell count } \\
(\text { cells } / \mu \mathrm{L})\end{array}$ & $\begin{array}{l}237.1(125.4) \\
194[69-534]\end{array}$ & $\begin{array}{l}245.2(127.9) \\
220[87-1091]\end{array}$ & $\begin{array}{l}238.7(126.9) \\
218.5[15-859]\end{array}$ & $\begin{array}{l}223.0(124.6) \\
200[0-1070]\end{array}$ & $\begin{array}{l}210.9(129.0) \\
180[0-1520]\end{array}$ & $\begin{array}{l}225.8(127.5) \\
200.0[0-1520]\end{array}$ \\
\hline EDSS $^{\mathrm{a}}$ & $\begin{array}{l}2.9(1.2) \\
3.0[1.0-5.0]\end{array}$ & $\begin{array}{l}2.3(1.2) \\
2.0[0.0-5.5]\end{array}$ & $\begin{array}{l}3.0(1.3) \\
2.5[0.0-5.5]\end{array}$ & $\begin{array}{l}3.0(1.4) \\
3.0[0.0-6.0]\end{array}$ & $\begin{array}{l}2.9(1.3) \\
3.0[0.0-6.0]\end{array}$ & $\begin{array}{l}2.8(1.3) \\
2.5[0.0-6.0]\end{array}$ \\
\hline $\begin{array}{l}\text { Number of relapses } \\
\text { in the previous } 2 \\
\text { years }\end{array}$ & $2.4(1.5) ; 2[1-6]$ & $1.8(0.9) ; 2[1-5]$ & $2.3(1.9) ; 2$ [0-22] & $2.1(1.2) ; 2$ [0-9] & $2.0(1.3) ; 2[0-8]$ & $2.1(1.4) ; 2[0-22]$ \\
\hline \multicolumn{7}{|c|}{ Gd-enhancing T1 lesions count } \\
\hline & $\begin{array}{l}0.5(0.8) \\
0[0-2]\end{array}$ & $\begin{array}{l}3.2(7.1) \\
1[0-75]\end{array}$ & $\begin{array}{l}1.5(5.0) \\
0[0-60]\end{array}$ & $\begin{array}{l}1.7(4.9) \\
0[0-47]\end{array}$ & $\begin{array}{l}1.6(4.1) \\
0[0-58]\end{array}$ & $\begin{array}{l}1.9(5.1) \\
0[0-75]\end{array}$ \\
\hline $\begin{array}{l}\text { Patients with at } \\
\text { least } 1 \text { Gd- } \\
\text { enhancing T1 } \\
\text { lesion (\%) }\end{array}$ & 32.0 & 51.1 & 37.7 & 37.4 & 43.9 & 41.6 \\
\hline $\begin{array}{l}\text { Volume of T2 } \\
\text { lesions }\left(\mathrm{cm}^{3}\right)\end{array}$ & $\begin{array}{l}10.2(9.0) \\
9.3[0.3-28.7]\end{array}$ & $\begin{array}{l}10.9(12.6) \\
6.8[0.0-111.3]\end{array}$ & $\begin{array}{l}13.6(16.7) \\
7.1[0.1-129.4]\end{array}$ & $\begin{array}{l}13.2(13.3) \\
8.8[0.1-85.9]\end{array}$ & $\begin{array}{l}14.3(14.2) \\
9.0[0.1-81.9]\end{array}$ & $\begin{array}{l}13.2(14.2) \\
8.1[0.0-129.3]\end{array}$ \\
\hline
\end{tabular}

Eligibility was assessed at the screening visit

For continuous covariates, mean (SD) and median [range] are reported

$A I$ auto-injector, EDSS Expanded Disability Status Scale, $G d$-enhancing gadolinium-enhancing, $I V$ intravenous, $N$ number of patients included in the PK-B cell analysis, $n$ number of patients in each ethnic group, $P F S$ prefilled syringe, $S C$ subcutaneous, $S D$ standard deviation,

${ }^{a}$ Baseline EDSS score was defined as the score at the last assessment before the first dose administration of trial drug

\subsubsection{B Cell Data}

A total of 17,158 B cell samples provided by 1486 patients with RMS were included in the B cell analysis. Among these samples, 718 (4\%) were BLOQ from studies OMS 115102 and MIRROR. Studies OMS115102 and MIRROR provided information about the B cell depletion as well as repletion, while studies APLIOS and ASCLEPIOS I and II provided data corresponding mainly to depletion as nearly all patients remained on treatment for the period of time during which they provided data.

\subsubsection{Data Handling and Exploration}

Two participants had missing baseline B cell values, which were imputed to the median value of the population (200 cells $/ \mu \mathrm{L}$ ). Two other participants had baseline B cell values as 0 , which faced the numerical difficulty in log transformation when performing covariate analysis, and therefore were imputed as 1 . There was no other missing data in covariates.

A thorough immunogenicity assessment of ofatumumab based on data from all five studies was conducted (data on file). The overall incidence of positive anti-drug antibodies 
in patients with RMS was low $(<2 \%)$. This included $1.17 \%$ patients with pre-existing anti-drug antibodies, which is in line with the $1 \%$ false-positive target for defining the confirmatory cut-point. The proportion of patients with treatment-induced anti-drug antibodies was $0.5 \%$ (7/1476). There was no impact of positive anti-drug antibody titers on PK, safety profile, or B cell kinetics in any of the patients.

\subsection{B Cell Depletion Target}

Data from the dose-finding MIRROR study previously showed that the cumulative volume of new Gd-enhancing T1 lesions at week 24 depended on average B cell levels (weeks 4-20) (AAN 2017 [14]) (Savelieva et al., 2021; manuscript in preparation).

In the exploratory graphical analysis, $\mathrm{B}$ cell counts were divided into three groups $(\leq 8,>8-\leq 32,>32$ cells $/ \mu \mathrm{L})$, 8 cells $/ \mu \mathrm{L}$ being an arbitrarily chosen cut-off representing close to complete depletion. High levels of both CD19+ B cell numbers (average, weeks 4-20) and lesion counts at screening were associated with increased cumulative MRI lesion volumes by week 24 (Fig. 2). The largest reduction in the cumulative volume of new Gd-enhancing T1 lesions was observed when the B cell count was $\leq 8$ cells $/ \mu \mathrm{L}$ regardless of the presence of lesion activity at screening.

Model-based predictions were consistent with the findings of the graphical exploration (modeling results in poster AAN 2017 [14] available on demand). The negative binomial regression model confirmed that a consistent reduction in B cell count (e.g., $\leq 8$ cells $/ \mu \mathrm{L}$ ) yielded a superior control of cumulative Gd-enhancing T1 lesion volumes at week 24, even after correcting for Gd-enhancing T1 lesion count at screening; the efficacy of ofatumumab regimens was explained by its effect on B cell counts. This indicated that the dosage regimen could be selected based on its ability to achieve and maintain low levels of B cells. Since reduction of B cell count below 8 cells $/ \mu \mathrm{L}$ provided the best control in terms of lesion volumes, this level had been chosen as the B cell target (AAN 2017 [14]) (Savelieva et al., 2021; manuscript in preparation).

\subsection{PKPD Modeling}

\subsubsection{PK Model}

A quasi-steady state binding model with central and peripheral plasma compartments and a first order absorption for SC administration of ofatumumab adequately described ofatumumab PK. A slight increase of ofatumumab concentrations over time was observed in the phase 3 ASCLEPIOS studies (Supplementary Fig. 1, see the electronic supplementary material). This was described in the model by a time-dependent effect on the CD20 synthesis rate (visual predictive checks [VPC], Supplementary Fig. 2). Time-varying parameters were tested in the different models including $F, \mathrm{CL}$, or synthesis rate constant $\left(k_{\mathrm{syn}}\right)$ parameters. When the models were fitted with data from all five studies, the model with the time effect on $k_{\text {syn }}$ provided the best criterion value. It was decided to keep this model as the final model, though with certain limitations (see "Discussion").
Fig. 2 Cumulative volume of new $\mathrm{Gd}+\mathrm{T} 1$ lesions at week 24 by CD19+ B cell count and the number of $\mathrm{Gd}+\mathrm{T} 1$ lesions at screening. $G d+$ gadoliniumenhancing, $S E$ standard error

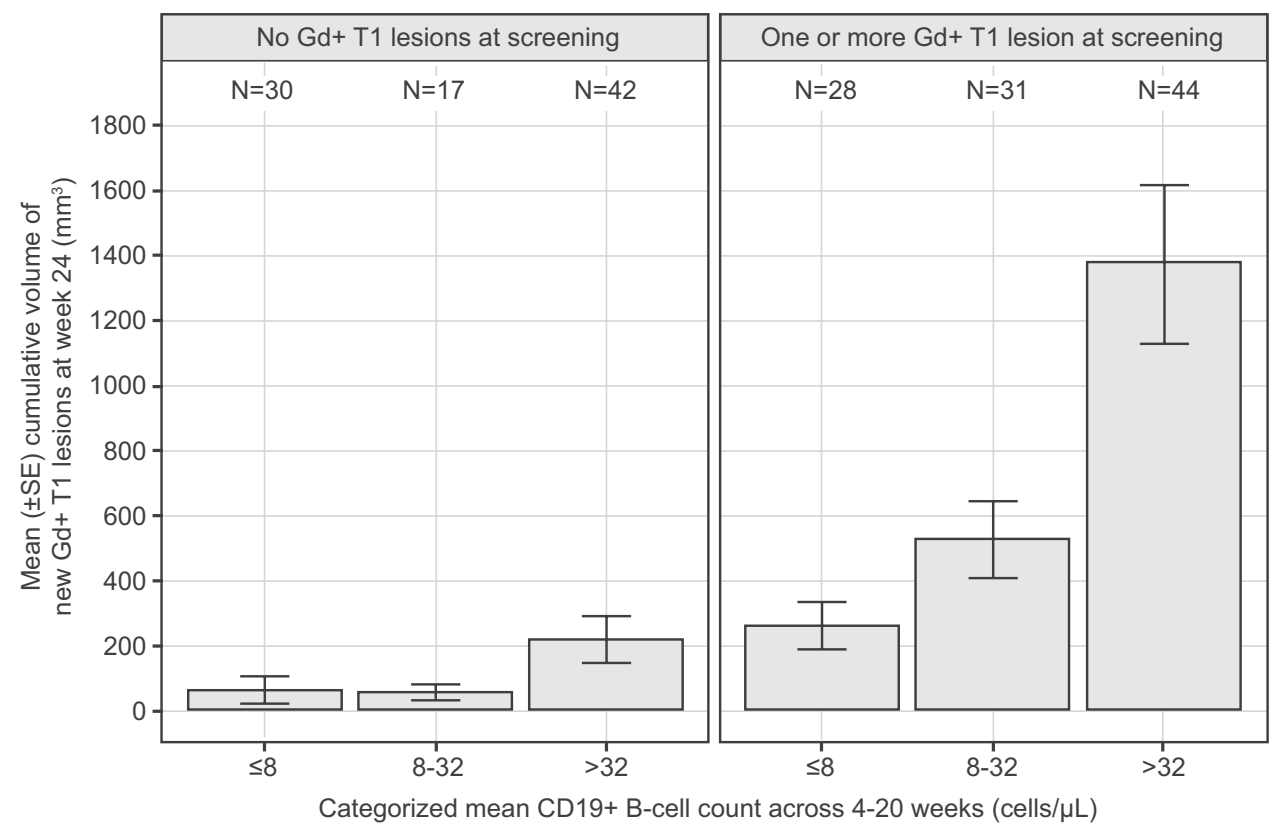


Covariates that were included in the final model were weight, route of administration (IV vs. SC [reference]) and injection device (AI vs. PFS [reference]) (Fig. 1).

\subsubsection{B Cell Model}

An indirect response model was selected to describe the stimulation of B cell lysis by free ofatumumab concentrations (sigmoid $E_{\max }$ function). Two B cell compartments were included and parameterized in terms of clearances and volumes; the hypothetical physiological spaces they represent in the body were the central compartment, as in the PK model, and a peripheral compartment specific to the B cells, which is different to the PK 'peripheral' compartment. Covariates included in the final model were weight, age, baseline B cell counts, and study (Fig. 1).

\subsubsection{Final Model Description}

A schematic representation of the compartments, their interactions, and the corresponding variables is given in Fig. 3 . The mathematical description for the final model is given below, and the PK and PD parameter estimates are displayed in Table 3.

A quasi-steady state approximation of the target mediated drug-disposition model with central and peripheral compartments was used to describe the observed ofatumumab plasma concentrations. The absorption was described by a first order input, and bioavailability was estimated for the SC administration. A time effect was included on $k_{\text {syn }}$ such that it decreased over time from an initial value, $k_{\text {syn } 0}$, to a steady state value, synthesis rate constant at time infinity $\left(k_{\text {synoo }}\right)$. The peripheral volume of distribution $\left(V_{\mathrm{p}}\right)$ was fixed to a typical value as reported in Ryman and Meibohm [19], and the dissociation constant $\left(K_{\mathrm{D}}\right)$ as well as the dissociation rate constant $\left(k_{\text {off }}\right)$ were fixed to preclinically estimated values. Inter-subject variability was included on all estimated PK parameters. Inter-subject random effects were assumed to be normally distributed on the log-transformed parameter scale, while the bioavailability was logit transformed. A block covariance structure was included on the PK parameters CL, $k_{\mathrm{a}}$, and $k_{\text {des }}$, and another block included on $k_{\text {syno }}$, receptor amount at baseline $\left(R_{0}\right)$, and $k_{\mathrm{e}(\mathrm{P})}$. The residual error was quantified by a combined proportional and additive error model. The B cell count model was related to the model predicted free ofatumumab concentrations through a sigmoid $E_{\max }$ function for the stimulation of B cell lysis in an indirect response model. Two B cell compartments were included and parameterized in terms of clearances and volumes. Inter-subject variability was included on all estimated PD parameters. A block covariance structure was included on the PD parameters $E_{\text {max }}$, B cell elimination rate constant $\left(k_{\text {out }}\right)$, and peripheral compartment for B cells $\left(V_{\mathrm{b}}\right)$. The residual error was quantified by a combined proportional and additive error model.
Fig. 3 Schematic structure of the final model. $E C_{50}$ concentration producing $50 \%$ of maximum drug effect, $E_{\max }$ maximum drug effect, $k_{d e g}$ receptor degradation rate constant, $k_{e(L)}$ elimination rate constant for ligand, $k_{e(P)}$ elimination rate constant for complex, $k_{i n}$ B cell input rate, $k_{\text {off }}$ dissociation rate constant, $k_{\text {on }}$ binding rate, $k_{\text {out }}$ B cell elimination rate constant, $k_{\text {syn }}$ synthesis rate constant, $L$ ligand, $Q$ intercompartmental flow, $Q B$ flow between B cell compartments, $V_{b}$ peripheral volume of distribution of B cells, $V_{c}$ central volume of distribution, $V_{p}$ peripheral volume of distribution of ofatumumab

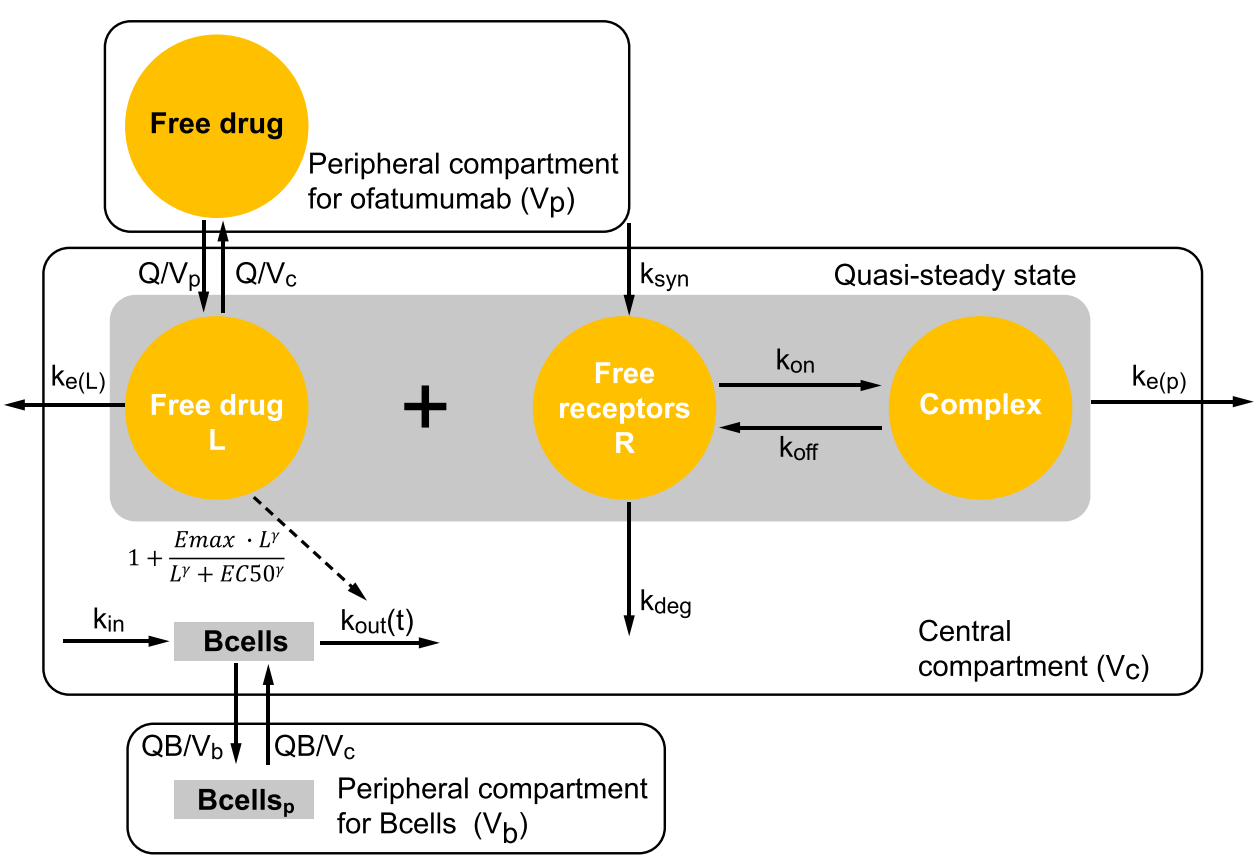


Table 3 PK and PD parameter estimates for the final model

\begin{tabular}{|c|c|c|c|c|}
\hline \multirow[t]{2}{*}{ Parameter (unit) } & \multirow[t]{2}{*}{ Estimate } & \multirow[t]{2}{*}{ RSE \% } & \multicolumn{2}{|c|}{ Inter-individual variability } \\
\hline & & & SD & $\begin{array}{l}\text { RSE (\%) } \\
\text { [Shrinkage } \\
\%]\end{array}$ \\
\hline$k_{\mathrm{a}}\left(\mathrm{day}^{-1}\right)$ & 0.157 & 5.80 & 0.652 & $3.95[52]$ \\
\hline$\beta\left(k_{\mathrm{a}}, 1 \mathrm{wt} 70\right)$ & -0.457 & 27.1 & - & \\
\hline$F(-)$ & 0.685 & 3.10 & 0.531 & $9.00[72]$ \\
\hline$V_{\mathrm{c}}(\mathrm{L})$ & 2.62 & 2.11 & 0.116 & 19.3 [NA] \\
\hline$\beta\left(V_{\mathrm{c}}, 1 \mathrm{wt} 70\right)$ & 1.2 & 8.66 & - & - \\
\hline$k_{\mathrm{e}(\mathrm{P})}\left(\right.$ days $\left.^{-1}\right)$ & 1.31 & 8.93 & 1.14 & $5.10[65]$ \\
\hline$\beta\left(k_{\mathrm{e}(\mathrm{P})}, \mathrm{AI}\right)$ & 0.713 & 22.2 & - & - \\
\hline$k_{\mathrm{syn} 0}(\mathrm{nmol} / \mathrm{L} /$ day $)$ & 0.985 & 5.91 & 0.0559 & $64.1[99]$ \\
\hline$\beta\left(k_{\mathrm{syn} 0}, \operatorname{lwt} 70\right)$ & -1.52 & 12.1 & - & - \\
\hline$R_{0}(\mathrm{nmol} / \mathrm{L})$ & 32.5 & 5.86 & 0.91 & $4.66[61]$ \\
\hline$\beta\left(R_{0}, \mathrm{AI}\right)$ & -0.544 & 21.5 & - & - \\
\hline$\beta\left(R_{0}, \mathrm{IV}\right)$ & 0.987 & 24.9 & - & - \\
\hline CL (L/day) & 0.34 & 2.99 & 0.486 & $4.66[53]$ \\
\hline$\beta(\mathrm{CL}, \mathrm{lwt} 70)$ & 1.52 & 4.87 & - & - \\
\hline$\beta(\mathrm{CL}, \mathrm{IV})$ & -1.07 & 10.9 & - & - \\
\hline$Q$ (L/day) & 0.358 & 10.9 & 0.705 & $27.3[81]$ \\
\hline$\beta(Q, \mathrm{IV})$ & -2.31 & NA & - & - \\
\hline$V_{\mathrm{p}}(\mathrm{L})$ & 2.8 & - & - & - \\
\hline$K_{\mathrm{D}}(\mathrm{nmol} / \mathrm{L})$ & 0.167 & - & - & - \\
\hline$k_{\text {off }}\left(\right.$ day $\left.^{-1}\right)$ & 5.53 & - & - & - \\
\hline$k_{\mathrm{des}}\left(\right.$ year $\left.^{-1}\right)$ & 2.58 & 5.69 & 0.654 & $7.01[58]$ \\
\hline$k_{\mathrm{syn} \infty}(\mathrm{nmol} / \mathrm{L} /$ day $)$ & 0.0554 & 36.3 & 2.16 & $10.3[64]$ \\
\hline$\beta\left(k_{\mathrm{syn} \infty}, \mathrm{IV}\right)$ & 2.49 & 25.3 & - & - \\
\hline$B_{0}($ cells $/ \mu \mathrm{L})$ & 194 & 1.25 & 0.394 & $2.63[26]$ \\
\hline$\beta\left(B_{0}\right.$,lage 38$)$ & -0.282 & 17.1 & - & - \\
\hline$\beta\left(B_{0}, 1 \mathrm{wt} 70\right)$ & 0.271 & 18.9 & - & - \\
\hline$E_{\max }(-)$ & 159 & 3.18 & 0.587 & $4.17[57]$ \\
\hline$\beta\left(E_{\max }, 1 \mathrm{Bc} 200\right)$ & 0.275 & 11.6 & - & - \\
\hline$\beta\left(E_{\max }\right.$, APLIOS $)$ & 0.503 & 9.35 & - & - \\
\hline $\mathrm{EC}_{50}(\mathrm{mg} / \mathrm{L})$ & 0.0057 & 8.52 & 0.927 & $9.68[81]$ \\
\hline Gamma (-) & 2.81 & 11.6 & 1.46 & $4.79[80]$ \\
\hline$k_{\text {out }}\left(\right.$ day $\left.^{-1}\right)$ & 0.0124 & 5.15 & 0.922 & $4.64[64]$ \\
\hline$\beta\left(k_{\text {out }}, \operatorname{lwt} 70\right)$ & -0.624 & 19.8 & - & - \\
\hline$\beta\left(k_{\text {out }}\right.$, MIRROR $)$ & -0.554 & 14.1 & - & - \\
\hline QB (L/day) & 0.78 & - & - & - \\
\hline$V_{\mathrm{b}}(\mathrm{L})$ & 3.7 & 6.26 & 1.37 & $5.16[51]$ \\
\hline Corr_ $V_{\mathrm{b} \_} E_{\max }$ & 0.28 & 22.6 & & \\
\hline Corr $\_k_{\text {out }}-V_{\mathrm{b}}$ & -0.336 & 17.9 & & \\
\hline Corr $\_k_{\text {out }}-V_{\mathrm{b}}$ & 0.423 & 12.3 & & \\
\hline Corr_ $k_{\mathrm{a}-} \mathrm{CL}$ & -0.294 & 21.0 & & \\
\hline Corr $\_k_{\text {des }}-\mathrm{CL}$ & 0.642 & 10.4 & & \\
\hline Corr $\_k_{\mathrm{des}}-k_{\mathrm{a}}$ & 0.433 & 23.2 & & \\
\hline Corr $\_k_{\mathrm{e}(\mathrm{P})-} R_{0}$ & -0.551 & 8.69 & & \\
\hline Corr_ $k_{\text {syn } \infty-} R_{0}$ & 0.47 & 13.6 & & \\
\hline Corr $\_k_{\text {syn } \infty-} k_{\mathrm{e}(\mathrm{P})}$ & -0.464 & 13.6 & & \\
\hline Ofatumumab conc. additive (mg/L) & 0.0316 & 3.28 & & \\
\hline
\end{tabular}


Table 3 (continued)

\begin{tabular}{llll}
\hline Parameter (unit) & Estimate & RSE \% & \begin{tabular}{c} 
Inter-individual variability \\
\cline { 2 - 2 }
\end{tabular} \\
\hline Ofatumumab conc. proportional & & $\begin{array}{c}\text { RSE }(\%) \\
{[\text { Shrinkage }} \\
\%]\end{array}$ \\
B cell count additive (cells $/ \mu \mathrm{L})$ & 0.278 & 1.72 \\
B cell count proportional & 0.153 & - & - \\
\hline
\end{tabular}

$B_{0}$ baseline B cell count, $C L$ clearance, conc. concentration, $E C_{50}$ concentration producing $50 \%$ of maximum drug effect, $E_{\max }$ maximum drug effect, $F$ bioavailability, Gamma sigmoidicity parameter for drug effect in indirect model, $I V$ intravenous, $k_{a}$ absorption rate constant, $K_{D}$ dissociation constant, $k_{\text {des }}$ time rate constant on $k_{\mathrm{syn}}, k_{e(P)}$ elimination rate constant for complex, $k_{\text {off }}$ dissociation rate constant, $k_{\text {out }} \mathrm{B}$ cell elimination rate constant, $k_{s y n}$ synthesis rate constant, $k_{\text {syn } 0}$ synthesis rate constant at time $0, k_{\text {syno }}$ synthesis rate constant at time infinity, $L$ liter, $l w t 70$ logtransformed body weight normalized to $70 \mathrm{~kg}, N A$ not available, $P$ drug-receptor complex, $P D$ pharmacodynamic, $P K$ pharmacokinetic, $Q$ intercompartmental flow, $Q B$ flow between B cell compartments, $R_{0}$ receptor amount at baseline, $R S E$ relative standard error, $S D$ standard deviation, $V_{b}$ peripheral volume of distribution of B cells, $V_{c}$ central volume of distribution, $V_{p}$ peripheral volume of distribution of ofatumumab, $\beta$ covariate effect

For the PK part of the model, the equations are:

$\frac{\mathrm{dA}}{\mathrm{dt}}=-k_{a} A$, where $A$ is the amount of ofatumumab at absorption site

$\frac{\mathrm{d} L_{\mathrm{P}}}{\mathrm{d} t}=k_{\mathrm{cp}} L_{\mathrm{C}}-k_{\mathrm{pc}} L_{\mathrm{P}}$, where $L_{p}$ and $L_{c}$ are

the concentrations of drug in the peripheral

and central compartments, respectively,

and $k_{c p}$ and $k_{p c}$ the rate

constants of drug transfer between central

and peripheral / peripheral

and central compartments, respectively

$\frac{\mathrm{d} L_{\mathrm{tot}}}{\mathrm{d} t}=\frac{k_{a} A}{V_{\mathrm{c}}}-\left(k_{\mathrm{e}(\mathrm{L})}-k_{\mathrm{e}(\mathrm{P})}+k_{\mathrm{cp}}\right) L_{\mathrm{C}}-k_{\mathrm{e}(\mathrm{P})} L_{\mathrm{tot}}+k_{\mathrm{pc}} L_{\mathrm{P}}$,

where $L_{\text {tot }}$ is the total concentration of unbound

and bound drug in the central compartment

and $k_{e(L)}$ the elimination rate constant of the unbound

drug concentration

$\frac{\mathrm{d} R_{\mathrm{tot}}}{\mathrm{d} t}=k_{\mathrm{syn}}(t)-k_{\mathrm{deg}} R_{\mathrm{tot}}-\left(k_{\mathrm{e}(\mathrm{P})}-k_{\mathrm{deg}}\right)\left(L_{\mathrm{tot}}-L_{\mathrm{C}}\right)$,

where $R_{\text {tot }}$ is the total number of receptors and $k_{\text {deg }}$

the target receptor degradation rate constant

$L_{\mathrm{C}}=\frac{1}{2}\left[\left(L_{\mathrm{tot}}-R_{\mathrm{tot}}-K_{\mathrm{S}}\right)+\sqrt{\left(L_{\mathrm{tot}}-R_{\mathrm{tot}}-K_{\mathrm{S}}\right)^{2}+4 L_{\mathrm{tot}} K_{\mathrm{S}}}\right]$,

where Ks is the quasi - steady state constant
$A(0)=F \times D, L_{\text {tot }}(0)=0, L_{\mathrm{P}}(0)=0, R_{\mathrm{tot}}(0)=R_{0}$,

where $F=S C$ bioavailability; $D=$ dose;

$R_{0}=$ total number of receptors at time 0

$k_{\mathrm{syn}}(t)=k_{\mathrm{syn} \infty}+\left(k_{\mathrm{syn} 0}-k_{\mathrm{syn} \infty}\right) e^{-\frac{k_{\mathrm{des}} t}{365.25}}$, where $t$ is the time

$k_{\mathrm{e}(\mathrm{L})}=\frac{\mathrm{CL}}{V_{\mathrm{c}}}, k_{\mathrm{cp}}=\frac{Q}{V_{\mathrm{c}}}, k_{\mathrm{pc}}=\frac{Q}{V_{\mathrm{p}}}$, where $L$ is the unbound

drug concentration for both compartments

$k_{\mathrm{on}}=\frac{k_{\mathrm{off}}}{K_{\mathrm{D}}}, K_{\mathrm{S}}=\frac{k_{\mathrm{e}(\mathrm{P})}+k_{\mathrm{off}}}{k_{\mathrm{on}}}, k_{\mathrm{deg}}=\frac{k_{\mathrm{syn}}(t)}{R_{0}}$.

For the PD part of the model the equations are:

$\frac{\mathrm{d} B}{\mathrm{~d} t}=k_{\text {in }}-k_{\text {out }}(1+\operatorname{stim}(L)) B-\frac{Q B}{V_{\mathrm{c}}} B+\frac{Q B}{V_{\mathrm{b}}} B_{\mathrm{p}}$,

where $Q B=$ flow between $B$ cell compartments;

$B=$ central compartment B cell count;

$B_{p}=$ peripheral compartment $B$ cell count;

stim = lysis stimulatory effect function

$\frac{\mathrm{d} B_{\mathrm{p}}}{\mathrm{d} t}=\frac{Q B}{V_{\mathrm{c}}} B-\frac{Q B}{V_{\mathrm{b}}} B_{\mathrm{p}}$

$\operatorname{stim}(L)=\frac{E_{\max } L^{\gamma}}{E L_{50}^{\gamma}+L^{\gamma}}$, where EL50 = Ltot concentration

achieving 50 percent of maximum lysis

stimulatory effect and $\gamma$ is the sigmoidicity

parameter 
$B(0)=\mathrm{Bcell0}$ and $B_{\mathrm{p}}(0)=B$ cell0 $\frac{V_{\mathrm{b}}}{V_{\mathrm{c}}}$, where Bcello is the observed central compartment $B$ cell count at time 0 .

The covariate model equations are:

$\log \left(k_{a, i}\right)=\log \left(k_{a}\right)+\beta_{\left(k_{a}, \mathrm{WT}_{70}\right)} \log \left(\frac{\mathrm{WT}_{i}}{70}\right)+\operatorname{eta}_{k_{a}, i}$,

where $\beta$ is the covariate effect, WT the body

weight and eta the individual level random effect

$$
\begin{aligned}
& \log \left(V_{c, i}\right)=\log \left(V_{c}\right)+\beta_{\left(V_{c}, \mathrm{WT}_{70}\right)} \log \left(\frac{\mathrm{WT}_{i}}{70}\right)+\operatorname{eta}_{V_{c}, i}, \\
& \log \left(k_{\mathrm{e}(\mathrm{P}), i}\right)=\log \left(k_{\mathrm{e}(\mathrm{P})}\right)+\beta_{\left(k_{\mathrm{e}(\mathrm{P})}, \mathrm{AI}\right)}\left[\text { Formulation }_{i}=\mathrm{AI}\right] \\
& +\operatorname{eta}_{k_{\mathrm{e}(\mathrm{P})}, i} \text {, } \\
& \log \left(k_{\mathrm{syn} 0, i}\right)=\log \left(k_{\mathrm{syn} 0}\right)+\beta_{\left(k_{\mathrm{syn} 0}, \mathrm{WT}_{70}\right)} \log \left(\frac{\mathrm{WT}_{i}}{70}\right)+\operatorname{eta}_{k_{\mathrm{syn} 0}, i}, \\
& \log \left(R_{0, i}\right)=\log \left(R_{0}\right)+\beta_{\left(R_{0}, \mathrm{AI}\right)}\left[\text { Formulation }_{i}=\mathrm{AI}\right]+\beta_{\left(R_{0}, \mathrm{IV}\right)} \\
& {\left[\text { Adminroute }_{i}=\mathrm{IV}\right]+\text { eta }_{R_{0}, i} \text {, }} \\
& \log \left(\mathrm{CL}_{i}\right)=\log (\mathrm{CL})+\beta_{\left(\mathrm{CL}, \mathrm{WT}_{70}\right)} \log \left(\frac{\mathrm{WT}_{i}}{70}\right) \\
& +\beta_{(\mathrm{CL}, \mathrm{IV})}\left[\text { Adminroute }_{i}=\mathrm{IV}\right]+\text { eta }_{\mathrm{CL}, i} \text {, }
\end{aligned}
$$

$\log \left(Q_{i}\right)=\log (Q)+\beta_{(Q, \mathrm{IV})}\left[\right.$ Adminroute $\left._{i}=\mathrm{IV}\right]+$ eta $_{Q, i}$,

$$
\begin{aligned}
\log \left(k_{\mathrm{syn} \infty, i}\right)= & \log \left(k_{\text {syn } \infty}\right)+\beta_{\left(k_{\text {syno }}, \text { IV }\right)}\left[\text { Adminroute }_{i}=\mathrm{IV}\right] \\
& +\operatorname{eta}_{k_{\text {syno } \infty}, i},
\end{aligned}
$$

$\log \left(B_{0, i}\right)=\log \left(B_{0}\right)+\beta_{\left(B_{0}, \mathrm{WT}_{70}\right)} \log \left(\frac{\mathrm{WT}_{i}}{70}\right)$

$+\beta_{\left(B_{0}, \mathrm{Age}_{38}\right)} \log \left(\frac{\mathrm{Age}_{i}}{38}\right)+\operatorname{eta}_{B_{0}, i}$, where $B_{0}$ is the estimated

central compartment $B$ cell count at time 0

$$
\begin{aligned}
\log \left(E_{\text {max }, i}\right)= & \log \left(E_{\text {max }}\right)+\beta_{\left(E_{\text {max }}, B \text { cello }_{200}\right)} \log \left(\frac{B \operatorname{cellO}_{i}}{200}\right) \\
& +\beta_{\left(E_{\max }, \text { Study }_{2102}\right)}\left[\operatorname{Study}_{i}=\text { APLIOS }\right]+\operatorname{eta}_{E_{\text {max }}, i} \\
\log \left(k_{\text {out }, i}\right)= & \log \left(k_{\text {out }}\right)+\beta_{\left(k_{\text {out }}, \text { WT }_{70}\right)} \log \left(\frac{\mathrm{WT}_{i}}{70}\right) \\
& +\beta_{\left(k_{\text {out }}, \text { Study }_{2831}\right)}\left[\text { Study }_{i}=\text { MIRROR }\right]+\operatorname{eta}_{k_{\text {out }}, i} .
\end{aligned}
$$

And the residual error models were:
$L_{\mathrm{tot}}=\left(f\left(t_{i j}, \psi_{i}\right)\left(1+b_{L_{\mathrm{tot}}}\right)+a_{L_{\mathrm{tot}}}\right) \varepsilon_{L \mathrm{tot}, i j}$,

where $f=$ function describing time course of

drug concentrations or B cell count; $\psi=$ vector

of all PKPD model parameters; $a_{L t o t}=$ additive

residual standard deviation for Ltot;

$b_{\text {Ltot }}=$ proportional residual standard deviation

for Ltot $; \epsilon$ Ltot $=$ residual error term for

the total ofatumumab concentrations

$B=\left(f\left(t_{i j}, \psi_{i}\right)\left(1+b_{B}\right)+a_{B}\right) \varepsilon_{B, i j}$ and $\varepsilon_{L \text { tot }, i j} \sim N(0,1)$

and $\varepsilon_{B, i j} \sim N(0,1)$, where $a_{B}=$ additive residual

standard deviation for $B$ cell count $; b_{B}=$ proportional

residual standard deviation for $B$ cell count;

$\epsilon_{B}=$ residual error term for $B$ cell count

In the equations, $i$ is for the individual and $j$ indexes the longitudinal observations, $\psi_{i}$ is the parameter vector of the structural model $f$ for individual $i$, eta ${ }_{i}$ describes the intersubject variability, and $\varepsilon i j$ is the residual error.

The covariates that were included in the final model were weight effects on the PK parameters $k_{\mathrm{a}}, \mathrm{CL}, V_{\mathrm{c}}$, and $k_{\text {syn } 0}$, and on the PD parameters $B_{0}$ and $k_{\text {out }}$; IV administration route effect on the PK parameters $R_{0}$, CL, $Q$, and $k_{\mathrm{syn} \infty}$; an AI device effect on the PK parameters $k_{\mathrm{e}(\mathrm{P})}$ and $R_{0}$; an age effect on the PD parameter $B_{0}$; a baseline B cell count effect on the PD parameter $E_{\max }$; a study APLIOS effect on the PD parameter $E_{\max }$; and a study MIRROR effect on the PD parameter $k_{\text {out }}$. The parameter estimates (Table 3 ) are based on a run of three chains, each with 1500 iterations. Nearly all the relative standard errors (RSEs) were less than 20\%, except for $k_{\text {synoo }}$, the weight effect on $k_{\mathrm{a}}$, AI effect on $k_{\mathrm{e}(\mathrm{P})}$ and $R_{0}$, IV administration route effect on $R_{0}$ and $k_{\text {syno }}$, interindividual variability standard deviation on $Q$ and $k_{\mathrm{syn} 0}$, and the correlation between $V_{\mathrm{b}}$ and $E_{\mathrm{max}}, k_{\mathrm{a}}$, and CL, and $k_{\mathrm{des}}$ and $k_{\mathrm{a}}$. The highest RSE was $64.1 \%$ on the inter-individual variability standard deviation on $k_{\mathrm{syn} 0}$.

The VPC as well as the observed versus predicted concentrations for the final model are given in the electronic supplementary material (Supplementary Figs. 2 and 3). The model parameters were overall well-estimated (except $k_{\text {syno }}$ ), and the goodness-of-fit diagnostics were acceptable.

\subsection{PKPD Simulation}

\subsubsection{Dose-Response Relationship}

Simulated B cell counts by time versus ofatumumab dose $(1,2,5,10,20$, or $40 \mathrm{mg})$ administered with the standard monthly schedule (including three initial weekly loading 


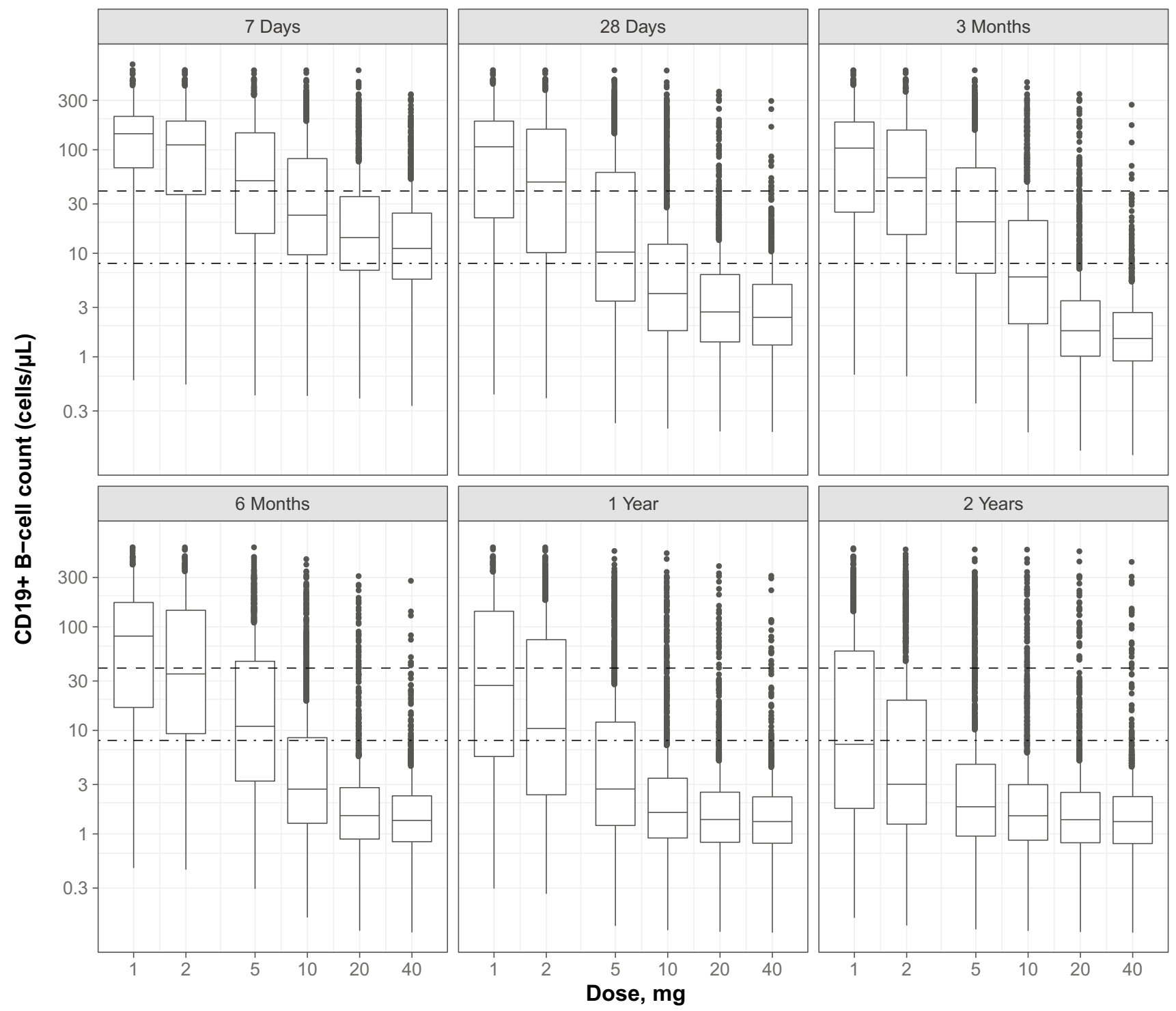

Fig. 4 Relationship between ofatumumab doses and B cell depletion at 7 days, 28 days, 3 months, 6 months, 1 year, and 2 years. Box and whisker plots of simulated B cell counts (middle line = median; box $=25$ th and 75th quartiles $[\mathrm{IQR}]$; lower/upper lines $=1.5 \times \mathrm{IQR}$; points $=$ outliers); simulations performed for the various dosage regimens administered SC with the prefilled syringe with the standard

doses) are shown in Fig. 4. Overall, the 20-mg dose appeared to be associated with an optimal level of B cell depletion compared to the other simulated doses. For each time point at which B cell depletion was evaluated, no further benefits were observed beyond the $20-\mathrm{mg}$ dose, while the $10-\mathrm{mg}$ dose did not appear to achieve a similar level of depletion as the 20-mg dose until after 6 months. In addition, the B cell variability between patients is lower with the 20-mg dose than with $10 \mathrm{mg}$, and not much higher than between-patient variability at $40 \mathrm{mg}$. This indicates that there is a higher proportion of patients who do not achieve the target B cell phase 3 schedule (i.e., three loading doses given weekly followed by monthly doses) and for the patient population included in the five studies. The dashed line indicates the B cell counts at lower limit of normal level $(40$ cells $/ \mu \mathrm{L})$; the dash-dotted line indicates the B cell target $(8$ cells $/ \mu \mathrm{L}) . I R Q$ interquartile range, $S C$ subcutaneously

depletion with $10 \mathrm{mg}$ compared with the $20 \mathrm{mg}$ or higher doses.

\subsubsection{Concentration-Time (PK) Simulations}

Figure 5 shows the drug concentration-time profile over the first year of dosing with the 20-mg monthly (phase 3 ) regimen and after last dose at 2 years. The ofatumumab initial dosing regimen allowed rapid attainment of relevant pharmacological levels, as confirmed by rapid achievement of $\mathrm{B}$ cell target (presented in the next section). The subsequent 


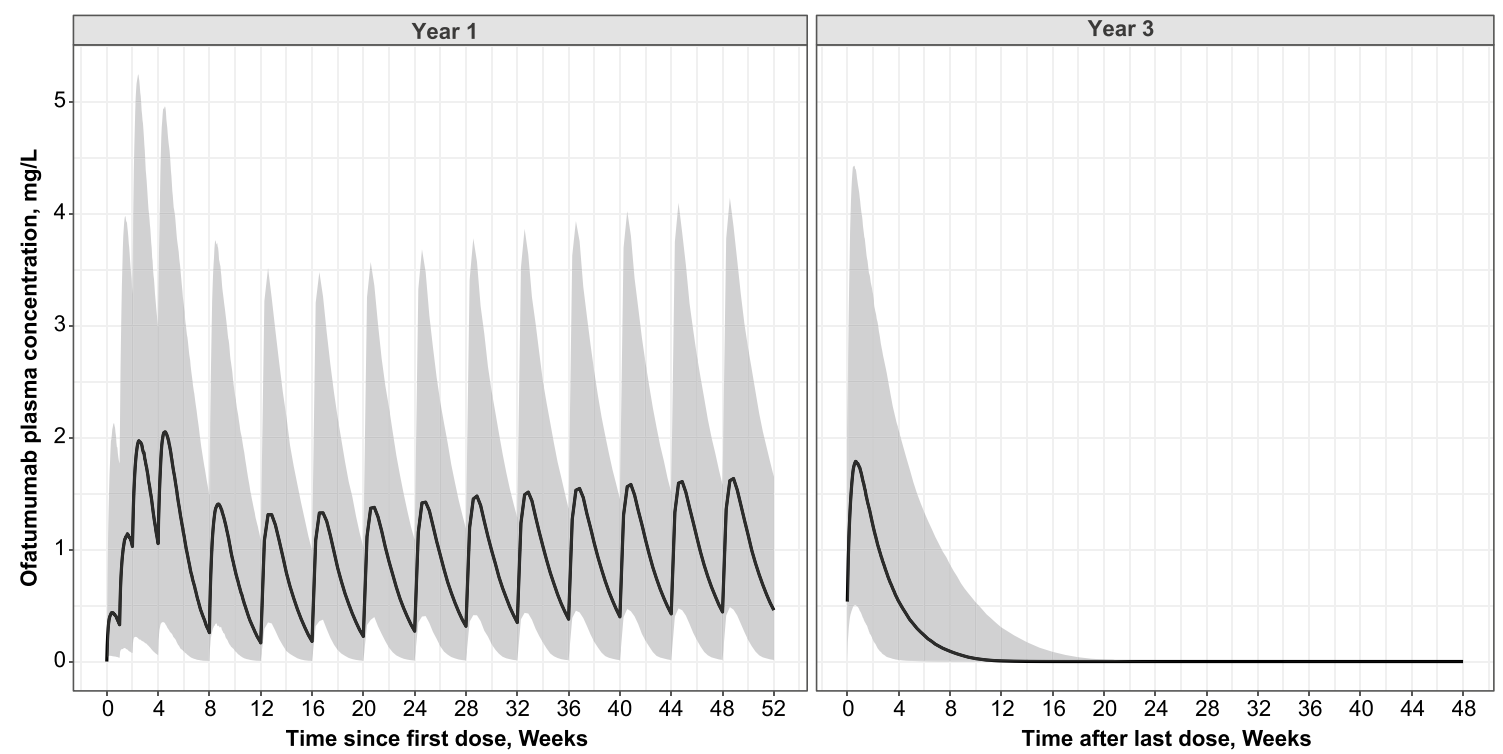

Fig. 5 Simulated ofatumumab plasma concentration-time profiles. Over 1 year (Left panel); after last dose at 2 years (Right panel). Simulated median and $90 \%$ prediction interval; simulations performed for the phase 3 dosage regimen administered SC with the pre- filled syringe (i.e., three loading 20-mg doses given weekly followed by monthly $20-\mathrm{mg}$ doses) and for the patient population included in the five studies

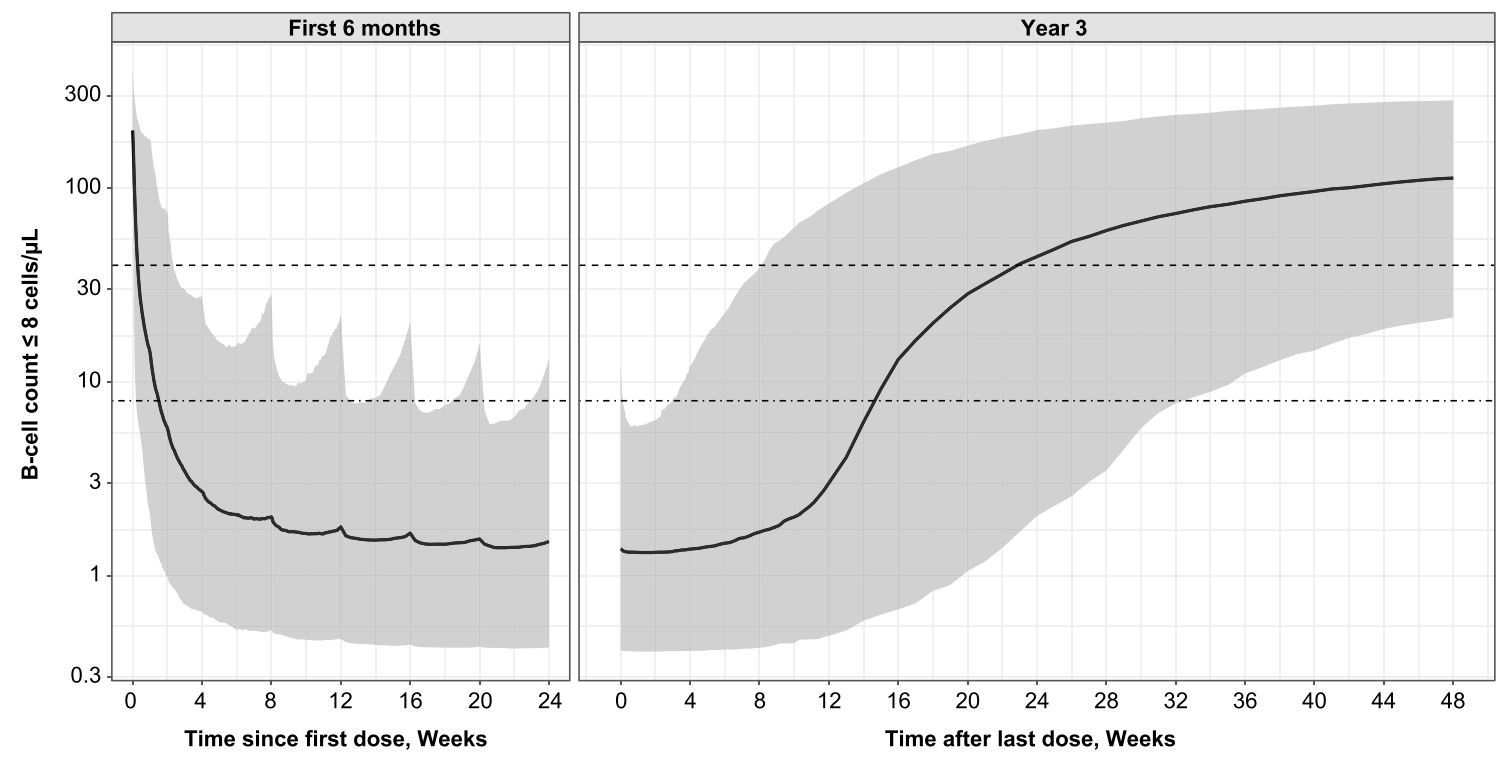

Fig. 6 Simulated B cell count. B cell depletion over the first 24 weeks of treatment (Left panel); B cell repletion after treatment stops after 2 years (Right panel). Simulated median B cell count and 90\% prediction interval; simulations performed for the phase 3 dosage regimen administered SC with the prefilled syringe (i.e., three loading

20-mg monthly maintenance regimen ensured sustained levels of exposure. In addition, the increase of ofatumumab concentrations over time is small and remains within the range of concentrations simulated within the first 12 weeks (84 days) of dosing. The half-life $\left(t_{1 / 2}\right)$ of ofatumumab as 20-mg doses given weekly followed by monthly 20-mg doses) and for the patient population included in the five studies. The dashed line indicates the B cell counts at lower limit of normal level (40 cells/ $\mu \mathrm{L})$; the dash-dotted line indicates the B cell target (8 cells $/ \mu \mathrm{L}) . S C$ subcutaneously

estimated based on the simulated PK profile at steady state is 11 days. The simulated median concentration profile decreased below LLOQ approximately 9 weeks (66 days) after the last dose (Fig. 5 right panel). 


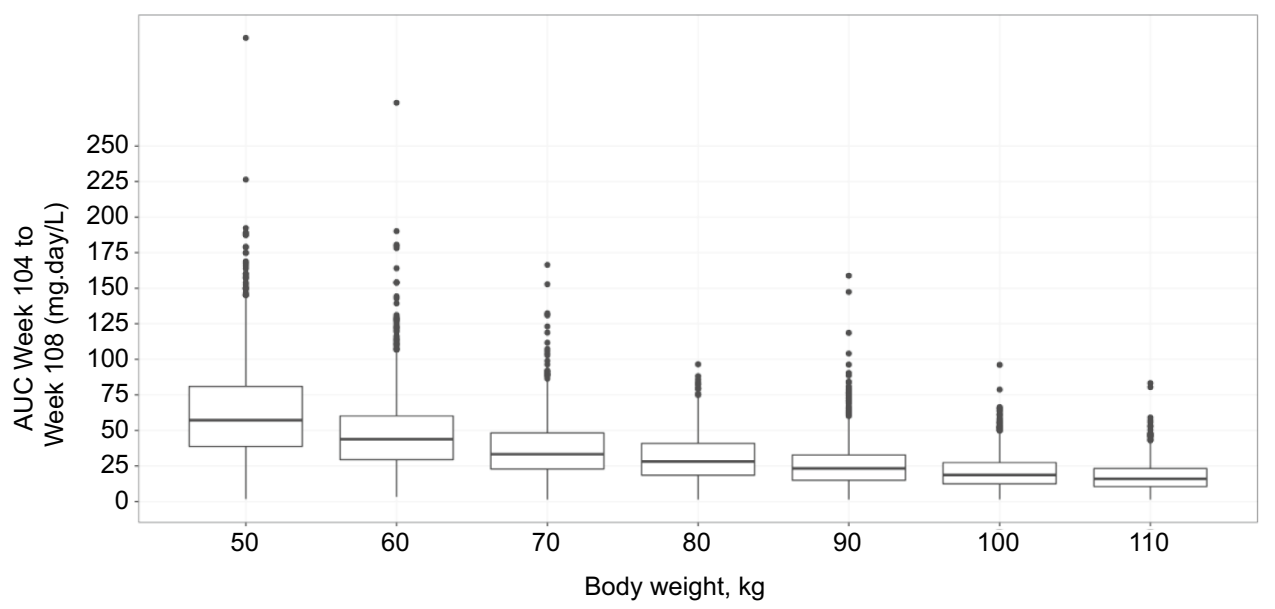

Fig. 7 Simulated steady state AUC week 104 to week 108 by weight. Box and whisker plots of AUCs calculated from individual patient simulated PK profiles (middle line $=$ median; box $=25$ th and 75 th quartiles [IQR]; lower/upper lines = $1.5 \times \mathrm{IQR}$; points = outliers);
PK profiles are for subcutaneous route with prefilled syringe and using phase 3 dosage regimen (i.e., three loading 20-mg doses given weekly followed by monthly $20-\mathrm{mg}$ doses). $A U C$ area under the curve, $I R Q$ interquartile range, $P K$ pharmacokinetic

Table 4 PK and B cell metrics as a function of baseline weight, age, and B cell count

Covariate $\quad$ AUC $(\mathrm{mg}$ day/L) $\quad$ B cell count at 2 years (day 728) Time to LLN (days)
(cells $/ \mu \mathrm{L})$

\begin{tabular}{llccc}
\hline Percentiles & Weight $(\mathrm{kg})$ & & \\
5th & 50 & $57.2[17.8-129.1]$ & $1.1[0.3-5.8]$ & $204.0[82.0-480.0]$ \\
Median & 70 & $33.3[10.6-76.8]$ & $1.3[0.4-7.3]$ & $164.0[61.1-425.8]$ \\
95 th & 110 & $16.0[3.4-37.4]$ & $1.6[0.5-30.8]$ & $128.0[32.9-364.0]$ \\
& Age (years) & & $1.6[0.5-8.6]$ & $156.0[52.0-388.4]$ \\
Minimum & 18 & $34.4[11.7-80.1]$ & $1.4[0.4-9.8]$ & $160.0[54.5-412.0]$ \\
Median & 38 & $34.6[9.5-78.3]$ & $1.2[0.3-7.1]$ & $172.0[70.0-454.4]$ \\
Maximum & 56 & $34.4[10.2-81.8]$ & & \\
& Cell count (cells $/ \mu \mathrm{L})$ & & $1.6[0.5-7.7]$ & $1.3[0.4-8.5]$ \\
5 th & 80 & $33.0[11.5-75.9]$ & $1.1[0.3-10.9]$ & $164.0[58.0-424.0]$ \\
Median & 200 & $34.7[9.6-76.1]$ & & $162.0[58.0-422.4]$ \\
95 th & 460 & $33.5[10.8-80.4]$ & & $16.8]$ \\
\hline
\end{tabular}

$A U C$ area under the curve, $L L N$ lower limit of normal ( 40 cells/ $\mu \mathrm{L}), P K$ pharmacokinetic

\subsubsection{B Cell Count Simulations}

B cell simulations with the 20-mg monthly regimen (including three initial weekly loading doses) demonstrated a rapid decrease in B cell count, achieving a median B cell depletion below 8 cells $/ \mu \mathrm{L}$ in 11 days, and converging to a median count of approximately 1.4 cells/ $\mu \mathrm{L}$ (Fig. 6 left panel). There were negligible signs of $\mathrm{B}$ cell repletion between doses, and over $94 \%$ of patients remained below the 8 cells $/ \mu \mathrm{L}$ at B cell steady state for pre-dose B cell counts. The median B cell count returned to the LLN of 40 cells/ $\mathrm{UL}$ less than 6 months (approximately 23 weeks) after dosing was interrupted at 2 years (Fig. 6 right panel).

\subsection{Effects of Covariates}

\subsubsection{Body Weight}

Based on the final PK-B cell model, baseline body weight displayed the largest covariate effect on the PK. The 5th and 95th percentiles of the observed baseline weights were $50 \mathrm{~kg}$ and $110 \mathrm{~kg}$, with simulations performed at $10-\mathrm{kg}$ intervals. The inter-dosing AUC at steady state (weeks 104-108) was $71.8 \%$ higher for a $50-\mathrm{kg}$ patient and $52.0 \%$ lower for a 110 $\mathrm{kg}$ patient relative to a $70-\mathrm{kg}$ patient (median weight) (Fig. 7 and Table 4).

However, body weight had a minimal impact on B cell levels (Table 4). The effect of body weight on ofatumumab 
Fig. 8 Proportion of CD19+ $\mathrm{B}$ cell depletion over time by patient weight quartile. Simulation is for subcutaneous route with prefilled syringe and using phase 3 dosage regimen (i.e., three loading 20-mg doses given weekly followed by monthly 20-mg doses)

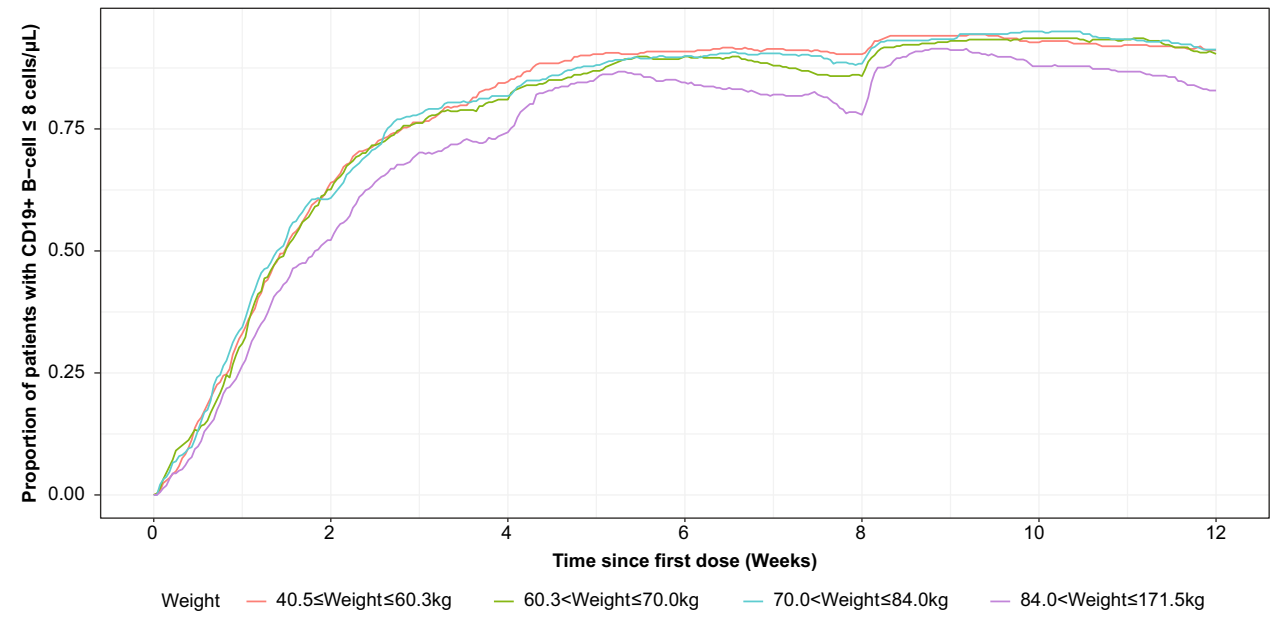

exposure translated into a negligible difference in the steady state pre-dose $\mathrm{B}$ cell count, ranging from 1 to 1.6 cells $/ \mu \mathrm{L}$ at 2 years (day 728; with a median B cell count of 1.3 cells/ $\mu L)$. Patients with a high body weight thus achieved close to complete B cell depletion to only marginally higher levels in patients with a lower body weight. Similarly, there was no relevant repletion between doses; B cell depletion was maintained regardless of patient weight.

This indicates that the ofatumumab effect on B cell depletion is relatively independent of the effect of body weight on PK for patients given the 20-mg dose regimen, as illustrated by Fig. 8. Weight was associated with a trend for increased B cell repletion times with decreasing weight, with repletion to LLN (40 cells/ $\mu \mathrm{L}$ ) reached within 18-29 weeks on average after the last dose across all body weight categories.

\subsubsection{Age}

The 5th and 95th percentiles of the observed baseline ages were 23 years and 52.8 years. Since these values were close to the minimum (18 years) and maximum (56 years), it was decided to simulate across the whole age range in 5-year intervals. Baseline age had negligible effect on PK exposure and B cell count, including B cell depletion and time to replete to 40 cells $/ \mu \mathrm{L}$ (Table 4 ).

\subsubsection{Baseline Cell Count}

The 5th and 95th percentiles of the observed baseline B cell count were 84 cells $/ \mu \mathrm{L}$ and 460 cells $/ \mu \mathrm{L}$. This was approximated in the simulations as 80 cells $/ \mu \mathrm{L}$ and 460 cells $/ \mu \mathrm{L}$, with simulations performed at 60 cells $/ \mu \mathrm{L}$ intervals. Baseline $B$ cell counts had a negligible effect on $\mathrm{PK}-\mathrm{B}$ cell count metrics (Table 4). Overall, patients with higher baseline B cell levels did not take longer to deplete to B cell target level, and conversely patients with lower baseline B cell levels did not take longer to replete to LLN after the phase 3 ofatumumab regimen stopped.

\subsubsection{Injection Device}

Similarly, the injection device (PFS or AI) covariate had negligible effect on PK exposure and resulting B cell counts. The median ofatumumab concentration and B cell count profiles for the PFS and AI are largely superimposable (Supplementary Fig. 4, see the electronic supplementary material). This is in agreement with the main finding of APLIOS that the PFS and AI devices are bioequivalent [15].

The correlation coefficients between all the covariates were explored and were low.

\section{Discussion}

The results of the $\mathrm{PK}-\mathrm{B}$ cell modeling confirm that the ofatumumab monthly $20-\mathrm{mg}$ SC regimen, representing the regimen licensed for use in the US, the EU, and other countries to treat RMS, optimally depletes B cell levels across the MS patient population.

These findings were based on an analysis of the available phase $2 / 3$ data on the PK of ofatumumab and B cell levels obtained from 1486 patients, which were pooled to develop a model describing the PKPD relationship of ofatumumab concentrations and $\mathrm{B}$ cell levels.

In the final PK-B cell model, PK and B cell data were best described by two-compartment models including a central and a peripheral compartment. Both PK and B cells shared the same volume of distribution in the central compartment (representing blood plasma), but distribute differently to their respective peripheral compartments. The peripheral B cell compartment is likely to refer to the locations of B cells that are not in the blood, such as the lymph nodes and spleen and other non-blood tissues (i.e., the lymphoid 
network). A similarly compartmented model accounting for lymphocyte kinetics has been previously proposed [20]. Although B cell turnover may be difficult to compare between studies, as B cell kinetics may be influenced by many factors (e.g., subset of B cells, age, diseases), based on the best match in the patient population and $\mathrm{B}$ cell types, we have found the B cell elimination rate constant $\left(k_{\text {out }}\right)$ in our model to be in a similar range to that reported in the literature $(0.0124$ /day vs. 0.02 and 0.04 [21, 22]). The halflife of ofatumumab was estimated at 11 days based on our PK-B cell model, with the concentration decreasing below LLOQ in approximately 9 weeks after the last $20-\mathrm{mg}$ dose. This half-life is of the same order, although slightly less than, the half-time estimated in a previous population PK (popPK) analysis based on the same studies (16 days [6, 7]).

Data from the phase 2 MIRROR dose-finding study had previously been graphically analyzed and modeled to determine a target B cell level associated with maximized control of cumulative Gd-enhancing T1 lesion volume and provide rationale for dose selection in phase 3 ofatumumab trials (AAN 2017 [14], ACTRIMS-ECTRIMS 2017 [15]) (Savelieva et al., 2021; manuscript in preparation). A negative binomial model had been chosen for its capacity to characterize the skewed MRI lesion data and because this model was suggested as a preferred way to describe MRI data in MS [23]. Results showed that lower lesion volumes were associated with lower B cell counts, with the strongest effect of B cell depletion on new Gd-enhancing T1 cumulative lesion volumes observed at a depletion level of $\leq 8$ cells/ $\mu \mathrm{L}$ at week 24 , even after correcting for Gd-enhancing T1 lesion count at screening.

Simulations with the PK-B cell model using different doses of ofatumumab administered with the phase 3 regimen using the PFS confirmed that this predetermined B cell target was best achieved and sustained with the 20-mg dose regimen. B cell counts with the ofatumumab 20-mg monthly regimen reached 8 cells $/ \mu \mathrm{L}$ in approximately 11 days and remained low. Lower doses (10 $\mathrm{mg}$ monthly) took longer to achieve the B cell target, and this target was maintained in a smaller proportion of patients, while a higher dose of $40 \mathrm{mg}$ did not yield any apparent additional benefits. B cell count returned to the LLN of 40 cells $/ \mu \mathrm{L}$ in less than 6 months after discontinuation of the ofatumumab 20-mg regimen.

Although the clinical relevance remains to be established, the absence of B cell repletion between doses, as demonstrated with the monthly (q4w) 20-mg SC regimen, is a unique characteristic of ofatumumab. This is not the case with other anti-CD20 treatments, such as ocrelizumab, which shows partial repletion between infusions given every 6 months [24].

These modeling results should be assessed in combination with the results from the MIRROR dose-finding study [11] and initial modeling results of these data (Savelieva et al., 2021; manuscript in preparation), which had provided a rationale for the loading and maintenance dose regimen used in the PK-B cell simulations and in the phase 3 studies. In MIRROR, the 60-mg q4w dose had the fastest $B$ cell depletion and a rapid onset of efficacy, but this regimen (as well as the 60-mg q12w regimen) was associated with more adverse events than the lower dose regimens of $3 \mathrm{mg}$ or $30 \mathrm{mg} \mathrm{q} 12 \mathrm{w}$. In particular, serious post-injection systemic reactions reported on day 1, including a report of cytokine release syndrome, were observed only with the 60-mg dose regimens. Together these results justify the initial use of $3 \times 20 \mathrm{mg}$ during the first 14 days in the standard phase 3 monthly 20-mg regimen to achieve rapid but safe B cell depletion with improved tolerability for home administration.

The results of this model, based mostly on data obtained from a Caucasian population, were further compared with data from the phase 2 APOLITOS study including patients from Japan. The final population PK-B cell model for Japanese patients did not reveal any clinically relevant difference with the one for Caucasian patients (data on file), thus supporting the validity of the presented findings across ethnic groups.

In the second part of the PK-B cell analysis, baseline body weight was identified as a significant covariate on PK (with inter-dosing AUC at steady-state halved in patients weighing $110 \mathrm{~kg}$, and increased by more than $70 \%$ in patients weighing $50 \mathrm{~kg}$, compared to median weight of 70 $\mathrm{kg}$ ); however, this effect of weight on PK did not translate into any clinically relevant difference in B cell depletion levels across the weight range. This result suggests that no dose adjustment of the 20-mg standard regimen is required based on weight. All the other covariates, including age, baseline B cell counts, route of administration, and injector device, had negligible influence on both ofatumumab PK and B cell levels.

One possible limitation is the potential for biased simulations of long-term effect of ofatumumab on B cell kinetics since the estimated time effect on the synthesis rate constant $\left(k_{\mathrm{syn}}\right)$ reduces over time and does not return to its baseline value when dosing stops. The time effect on $k_{\text {syn }}$ nevertheless appeared to describe the data better than any of the alternative models we have tested. It can also be noted that many of the parameters of the PK-B cell model have high shrinkage because many of the individuals have mainly pre-dose samples coming from the phase 3 studies and MIRROR. Shrinkage here is determined as the ratio of the standard deviation of the empirical Bayes estimates (EBEs) to the model estimated inter-individual distribution standard deviation. It has, however, previously been demonstrated that the stochastic approximation version of expectation-maximization (SAEM) algorithm performs well in estimating the 
population inter-individual standard deviation under various sparse sampling designs [25].

The efficacy of the monthly $20-\mathrm{mg}$ dose regimen was confirmed by results of the pivotal phase 3 ASCLEPIOS studies, which showed a rapid and sustained B cell depletion to low levels associated with a strong reduction of relapses and a significant and clinically relevant reduction in disability worsening versus teriflunomide [12]. Notably, a recent meta-analysis found that ofatumumab $20 \mathrm{mg} \mathrm{SC}$ monthly is as effective as other highly efficacious monoclonal antibody therapies for RMS (i.e., alemtuzumab, natalizumab, and ocrelizumab) [26]. Consistent with our findings, the efficacy improvement of ofatumumab versus teriflunomide within the two ASCLEPIOS studies was similar across exploratory subgroups defined by sex, age, body weight, prior nonsteroid MS therapy, and baseline disability and disease activity [6, 7]. In particular, no consistent pattern between body weight and efficacy was noticed, and the efficacy of ofatumumab, including its effect on disability outcomes, clinical relapse frequency, and MRI lesion formation, was broadly similar across quartiles of body weight groups (data on file). This finding is consistent with the fact that in ASCLEPIOS, ofatumumab provided close to complete B cell depletion in all patients regardless of their weight quartile [12].

Ofatumumab's safety profile was overall favorable and easily manageable, with no important safety signals arising from the pivotal clinical trial program, thus further supporting the choice of the 20-mg dose regimen. Injectionrelated systemic reactions were observed in $20 \%$ of patients $(0.2 \%$ severe), with rates comparable with that observed for placebo-dummy injections after the first dose and no dose adjustment required [12]. Infusion reactions have been observed at higher rates with other B cell therapies, for example, in $34 \%$ of patients treated with ocrelizumab ( $1.7 \%$ severe and $0.1 \%$ life-threatening), with dose adjustment required and mandatory premedication of steroids and anti-histamines [27]. Altogether, the safety and tolerability data of ofatumumab thus support the suitability of the 20-mg $\mathrm{SC}$ monthly regimen for self-administration at home [12].

\section{Conclusion}

The present PKPD modeling confirms the choice of the ofatumumab licensed dosing regimen for treatment of RMS patients and additionally demonstrates that no dose adjustment is required based on patient characteristics or injection device.

Supplementary Information The online version contains supplementary material available at https://doi.org/10.1007/s40263-021-00895-w.
Acknowledgements Marie-Catherine Mousseau (Novartis Ireland) wrote the first draft and updated the subsequent versions under the guidance of the authors. The authors thank Irina Baltcheva for her input at data analysis stage.

\section{Declarations}

Funding The development of this publication was organized and funded by Novartis Pharma AG, who also paid the open access fee.

Conflict of interest Per Soelberg Sørensen has served on scientific advisory boards for Genmab (a co-developer of ofatumumab) and GlaxoSmithKline; has served on steering committees or independent data monitoring boards in clinical trials sponsored by Genmab, GlaxoSmithKline, Merck, Novartis, and TEVA; has also served on scientific advisory boards or has received speaker honoraria for Biogen, and Celgene/BMS; has received funding of travel for these activities; and has served as editor-in-chief of the European Journal of Neurology. Go to Neurology.org/N for full disclosures. Huixin Yu, Gordon Graham, Olivier J. David, Joseph M. Kahn, Marina Savelieva, Etienne Pigeolet, Ayan Das Gupta, Ratnakar Pingili, Roman Willi, Krishnan Ramanathan, Bernd C. Kieseier, Dieter A. Häring, and Morten Bagger are all employees of Novartis.

Ethics approval All five studies were conducted in compliance with the tenets of the Declaration of Helsinki. Approvals were obtained from the designated independent Ethics Committee or Institutional Review boards and all patients provided written informed consent before enrollment into the trials. The present analysis did not require additional ethical approval beyond the approvals given in the clinical study protocols, as these allowed for the use of anonymized data for secondary analyses.

Consent to participate All patients provided written informed consent before enrollment into the trials.

Consent for publication Not applicable.

Availability of data and material The reader is able to request the raw data (anonymized) and related documents (e.g., protocol, reporting and analysis plan, clinical study report) of the five studies that underlie the modeling results reported in this article by connecting to https:// www.clinicalstudydatarequest.com and signing a Data Sharing Agreement with Novartis. These will be made available to qualified external researchers, with requests reviewed and approved by an independent review panel on the basis of scientific merit.

Code availability All analyses and graphics were produced in Monolix (version 2019R2) and R (version 3.6.1).

Authors' contributions HY, GG and OJD generated the PK-B cell model, and MS and JMK generated the B cell-MRI model; RP, KR, $\mathrm{DAH}, \mathrm{MB}, \mathrm{JMK}$, and MS were involved in the study design. All the authors previously mentioned, as well as EP, ADG, RW, BCK, and PSS, were involved in data interpretation, critically reviewed and provided their final approval to the manuscript, and agree to be accountable for the work.

Open Access This article is licensed under a Creative Commons Attribution-NonCommercial 4.0 International License, which permits any non-commercial use, sharing, adaptation, distribution and reproduction in any medium or format, as long as you give appropriate credit to the original author(s) and the source, provide a link to the Creative Commons licence, and indicate if changes were made. The images or other third party material in this article are included in the article's Creative 
Commons licence, unless indicated otherwise in a credit line to the material. If material is not included in the article's Creative Commons licence and your intended use is not permitted by statutory regulation or exceeds the permitted use, you will need to obtain permission directly from the copyright holder. To view a copy of this licence, visit http://creativecommons.org/licenses/by-nc/4.0/.

\section{References}

1. Milo R. Therapies for multiple sclerosis targeting B cells. Croat Med J. 2019;60(2):87-98.

2. Häusser-Kinzel S, Weber MS. The role of B cells and antibodies in multiple sclerosis, neuromyelitis optica, and related disorders. Front Immunol. 2019;10:201.

3. Li R, Patterson KR, Bar-Or A. Reassessing B cell contributions in multiple sclerosis. Nat Immunol. 2018;19(7):696-707.

4. Wanleenuwat P, Iwanowski P. Role of B cells and antibodies in multiple sclerosis. Mult Scler Relat Disord. 2019;36:101416.

5. Sabatino JJ Jr, Zamvil SS, Hauser SL. B-cell therapies in multiple sclerosis. Cold Spring Harb Perspect Med. 2019;9(2): a032037.

6. Ofatumumab (Kesimpta ${ }^{\circledR}$ ) United States Prescribing Information. https://www.accessdata.fda.gov/drugsatfda_docs/label/2020/ 125326s070lbl.pdf. Accessed 3 Nov 2021.

7. Ofatumumab (Kesimpta $\left.{ }^{\circledR}\right)$ European Prescribing Information. https://www.ema.europa.eu/en/documents/product-information/ kesimpta-epar-product-information_en.pdf. Accessed 10 Nov 2021.

8. Klein C, Lammens A, Schäfer W, Georges G, Schwaiger M, Mössner E, et al. Epitope interactions of monoclonal antibodies targeting CD20 and their relationship to functional properties. MAbs. 2013;5(1):22-33.

9. Smith P, Kakarieka A, Wallstroem E. Ofatumumab is a fully human anti-CD20 antibody achieving potent B-cell depletion through binding a distinct epitope. ECTRIMS. 2016;2016:P1143.

10. Sorensen PS, Lisby S, Grove R, Derosier F, Shackelford S, Havrdova E, et al. Safety and efficacy of ofatumumab in relapsing-remitting multiple sclerosis: a phase 2 study. Neurology. 2014;82(7):573-81.

11. Bar-Or A, Grove RA, Austin DJ, Tolson JM, VanMeter SA, Lewis EW, et al. Subcutaneous ofatumumab in patients with relapsingremitting multiple sclerosis: The MIRROR study. Neurology. 2018;90(20):e1805-14.

12. Hauser SL, Bar-Or A, Cohen JA, Comi G, Correale J, Coyle PK, et al. Ofatumumab versus teriflunomide in multiple sclerosis. $\mathrm{N}$ Engl J Med. 2020;383(6):546-57.

13. Bar-Or A, Wiendl H, Montalban X, Alvarez E, Davydovskaya M, Delgado SR, et al. Rapid and sustained B-cell depletion with subcutaneous ofatumumab in relapsing multiple sclerosis: APLIOS, a randomized phase-2 study. Mult Scler. 2021;4:13524585211044480.
14. Savelieva M, Kahn J, Wallström E, Leppert D. Relationship between MRI lesion count and B-cell count reduction under ofatumumab treatment. Present AAN. 2017;P5(348):2017.

15. Savelieva M, Kahn J, Bagger M, D Meier, D Tomic, Leppert D, Wallström E. Comparison of the B-cell recovery time following discontinuation of anti-CD20 therapies, ECTRIMS Online library, October 25, 2017. https://onlinelibrary.ectrims-congress. eu/ectrims/2017/ACTRIMS-ECTRIMS2017/199644/david.leppe rt.comparison.of.the.b-cell.recovery.time.following.discontinu ation.html. Accessed 11 Jan 2022.

16. Handling censored data in Monolix. https://monolix.lixoft.com/ data-and-models/censoreddata/. Accessed 3 Nov 2021.

17. Struemper H, Sale M, Patel BR, Østergaard M, Österborg A, Wierda WG, et al. Population pharmacokinetics of ofatumumab in patients with chronic lymphocytic leukemia, follicular lymphoma, and rheumatoid arthritis. J Clin Pharmacol. 2014;54(7):818-27.

18. Dua P, Hawkins E, van der Graaf PH. A tutorial on target-mediated drug disposition (TMDD) models. CPT Pharmacomet Syst Pharmacol. 2015;4(6):324-37.

19. Ryman JT, Meibohm B. Pharmacokinetics of monoclonal antibodies. CPT Pharmacomet Syst Pharmacol. 2017;6(9):576-88.

20. Ternant D, Büchler M, Thibault G, Ohresser M, Watier H, Lebranchu $\mathrm{Y}$, et al. Influence of Fc $\gamma$ RIIIA genetic polymorphism on T-lymphocyte depletion induced by rabbit antithymocyte globulins in kidney transplant patients. Pharmacogenet Genom. 2014;24(1):26-34.

21. Pan S, Yu H, Surti A, Cheng I, Marks SD, Brogan PA, et al. Pharmacodynamics of rituximab on B lymphocytes in paediatric patients with autoimmune diseases. Br J Clin Pharmacol. 2019;85(8):1790.

22. Macallan DC, Wallace DL, Zhang Y, Ghattas H, Asquith B, de Lara C, et al. B-cell kinetics in humans: rapid turnover of peripheral blood memory cells. Blood. 2005;105(9):3633-40.

23. Sormani MP, Bruzzi P, Miller DH, Gasperini C, Barkhof F, Filippi M. Modelling MRI enhancing lesion counts in multiple sclerosis using a negative binomial model: implications for clinical trials. J Neurol Sci. 1999;163(1):74-80.

24. Food \& Drug Administration (FDA). Clinical pharmacology review for ocrelizumab. https://www.accessdata.fda.gov/ drugsatfda_docs/nda/2017/761053Orig1s000ClinPharmR.pdf. Accessed 13 Oct 2020.

25. Combes FP, Retout S, Frey N, Mentré F. Powers of the likelihood ratio test and the correlation test using empirical bayes estimates for various shrinkages in population pharmacokinetics. CPT Pharmacomet Syst Pharmacol. 2014;3(4): e109.

26. Samjoo IA, Worthington E, Drudge C, Zhao M, Cameron C, Haering D, et al. Comparison of ofatumumab and other diseasemodifying therapies for relapsing multiple sclerosis: a network meta-analysis. J Comp Eff Res. 2020 (in press).

27. Hauser SL, Bar-Or A, Comi G, Giovannoni G, Hartung HP, Hemmer B, et al. Ocrelizumab versus interferon beta-1a in relapsing multiple sclerosis. N Engl J Med. 2017;376(3):221-34. 